\title{
Assessment of drought tolerance of 49 switchgrass (Panicum virgatum) genotypes using physiological and morphological parameters
}

Yiming Liu', Xunzhong Zhang ${ }^{1 *}$, Hong Tran², Liang Shan², Jeongwoon Kim³ ${ }^{3}$ Kevin Childs ${ }^{3,4}$, Erik H. Ervin ${ }^{1}$, Taylor Frazier ${ }^{5}$ and Bingyu Zhao ${ }^{5^{*}}$

\begin{abstract}
Background: Switchgrass (Panicum virgatum L.) is a warm-season $\mathrm{C}_{4}$ grass that is a target lignocellulosic biofuel species. In many regions, drought stress is one of the major limiting factors for switchgrass growth. The objective of this study was to evaluate the drought tolerance of 49 switchgrass genotypes. The relative drought stress tolerance was determined based on a set of parameters including plant height, leaf length, leaf width, leaf sheath length, leaf relative water content $(R W C)$, electrolyte leakage (EL), photosynthetic rate $(\mathrm{Pn})$, stomatal conductance $\left(g_{s}\right)$, transpiration rate ( $\mathrm{Tr}$ ), intercellular $\mathrm{CO}_{2}$ concentration (Ci), and water use efficiency (WUE).

Results: SRAP marker analysis determined that the selected 49 switchgrass genotypes represent a diverse genetic pool of switchgrass germplasm. Principal component analysis (PCA) and drought stress indexes (DSI) of each physiological parameter showed significant differences in the drought stress tolerance among the 49 genotypes. Heatmap and PCA data revealed that physiological parameters are more sensitive than morphological parameters in distinguishing the control and drought treatments. Metabolite profiling data found that under drought stress, the five best drought-tolerant genotypes tended to have higher levels of abscisic acid (ABA), spermine, trehalose, and fructose in comparison to the five most drought-sensitive genotypes.

Conclusion: Based on PCA ranking value, the genotypes TEM-SEC, TEM-LoDorm, BN-13645-64, Alamo, BN-10860-61, BN-12323-69, TEM-SLC, T-2086, T-2100, T-2101, Caddo, and Blackwell-1 had relatively higher ranking values, indicating that they are more tolerant to drought. In contrast, the genotypes Grif Nebraska 28, Grenville-2, Central lowa Germplasm, Cave-in-Rock, Dacotah, and Nebraska 28 were found to be relatively sensitive to drought stress. By analyzing physiological response parameters and different metabolic profiles, the methods utilized in this study identified drought-tolerant and drought-sensitive switchgrass genotypes. These results provide a foundation for future research directed at understanding the molecular mechanisms underlying switchgrass tolerance to drought.
\end{abstract}

Keywords: Panicum virgatum, Germplasm, Drought tolerance, SRAP marker, Genetic diversity, PCA, Metabolites

\footnotetext{
*Correspondence: xuzhang@vt.edu; bzhao07@vt.edu

1 Department of Crop and Soil Environmental Science, Virginia Tech, 367

Smyth Hall, 185 Ag Quad Ln, Blacksburg, VA 24061, USA

${ }^{5}$ Department of Horticulture, Virginia Tech, 407 Latham Hall, 220 Ag Quad

Ln, Blacksburg, VA 24061, USA

Full list of author information is available at the end of the article
} 


\section{Background}

Switchgrass (Panicum virgatum L.) has been designated as a model bioenergy crop in the United States [1]. As a warm-season perennial grass native to North America, switchgrass produces substantial aboveground biomass and has adapted to grow over an extensive range of habitats [2, 3]. To avoid competition with food crops for arable land, switchgrass will primarily be grown on marginal land, of which millions of hectares are affected by drought [4]. Drought stress will be one of the major abiotic stresses encountered when growing switchgrass for use as a biofuel. Indeed, a recent study suggests that drought stress could be one major economic risk factor that limits biofuel production [5]. Therefore, a major goal of switchgrass breeding programs is to identify and select for genotypes with improved tolerance to drought stress [6].

Two distinct switchgrass ecotypes, lowland and upland, have been recognized and are generally defined based on their morphological characteristics and habitat preferences. Lowland ecotypes are mostly tetraploid $(2 n=4 \times=36)$, whereas upland ecotypes tend to be octaploid $(2 n=8 \times=72)$ with a few tetraploid exceptions [7]. In addition, lowland ecotypes are usually tall, coarse in leaf texture, and are adapted to grow in the flood plain region of North America. Alternatively, upland ecotypes are shorter, have finer leaves, and are predominantly found in the cooler climates of the northern United States $[8,9]$. Previous studies have evaluated a number of switchgrass germplasm cultivars in response to drought stress [4, 10, 11]. Jiang et al. [4] found that drought stress in the upland switchgrass cultivar Cave-in-Rock reduced tissue water content and leaf dry weight while simultaneously increasing total carotenoid concentration and electrolyte leakage. Interestingly, the values of these parameters returned to those similar to the control (wellwatered) plants after re-watering [4]. Under greenhouse conditions, Barney et al. [10] estimated that drought treatments $(-4.0$ and $-11.0 \mathrm{MPa})$ could decrease the height and number of tillers, as well as decrease the overall leaf area, of drought-stressed switchgrass plants. They also found that drought treatments reduced biomass yields by up to $80 \%$ [10]. In a field trial using the switchgrass cultivar Sunburst, drought stress reduced yields to approximately $26 \%$ of those obtained in a year with above-average precipitation [12]. Although upland switchgrass genotypes have generally been considered to be more drought tolerant than lowland genotypes [13, 14], lowland switchgrass cultivars have been reported to outperform upland cultivars under various adverse environmental conditions, including drought stress [10]. Thus, a more systematic evaluation of drought tolerance, one that examines a greater number of diverse lowland and upland switchgrass cultivars in a controlled manner, is required.

It is difficult to assess drought stress tolerance of a large collection of switchgrass germplasm based solely on the data collected from a drought treatment experiment, because there is significant genetic and phenotypic variation among switchgrass germplasms under non-stressed (control) conditions. The Drought Stress Index (DSI) is a method to evaluate the effect of drought stress on individual germplasm based on the difference between drought treatment and the control plants. DSI is calculated as DSI = (value of trait under stress condition)/ (value of trait under controlled condition) $\times 100$. This equation removes the effect of germplasm variation from the drought stress evaluation and can therefore be used to assess a large collection of germplasm simultaneously [15].

Drought stress has a wide range of effects on the morphological, physiological, and biochemical processes in plants, and it can negatively affect the productivity of both dry land and irrigated crops [16-18]. Droughttolerant plants usually possess a combination of distinct morphological and physiological characteristics such as reduced leaf area, an extensive root system, the ability to sustain high leaf tissue water potential, and maintenance of a higher chlorophyll content and photosynthetic efficiency under drought conditions [19, 20]. Physiological measurements such as leaf relative water content (RWC), electrolyte leakage (EL), photosynthetic rate (Pn), stomatal conductance $\left(\mathrm{g}_{\mathrm{s}}\right)$, transpiration rate $(\mathrm{Tr})$, and water use efficiency (WUE) have been widely used as markers for evaluating drought stress tolerance in various plant species [21, 22]. Plant hormones such as abscisic acid (ABA) and jasmonic acid (JA) play an important role in plant response to drought stress [23]. An increase in JA is required for $A B A$ levels to increase under drought conditions [24]. A recent study has shown that exogenous spraying of JA activates the plant antioxidant defense system and improves drought tolerance in some Brassica species [25]. Therefore, ABA and JA levels are routinely used as indicators of plant drought tolerance. In response to drought treatments, a variety of other metabolites are synthesized, including amino acids (e.g., proline) $[26,27]$, nonstructural carbohydrates (e.g., glucose, fructose, sucrose, raffinose, and trehalose), inositol and inositol-phosphates, polyamines (PAs) (e.g., putrescine, spermidine, and spermine), and glycine betaine (GB). Increased carbohydrate turnover has also been observed in drought-tolerant plants [27, 28]. Proline, sugars, and glycine betaine are osmotically neutral metabolites that play important roles in osmotic adjustment [29-32]. In 
guard cells, inositol phosphates can release vacuolar $\mathrm{Ca}^{2+}$ into the cytosol in response to drought stress [33]. Polyamines (PAs) are ubiquitous, nitrogen-containing polycationic compounds that are found in all eukaryotic cells. In plants, the most abundant PAs are putrescine, spermidine, and spermine, and an increase in PA levels has been closely correlated with drought tolerance [34-36]. Therefore, metabolic profiling of drought-stressed plants could help evaluate their tolerance to drought stress.

Various molecular markers have been used to evaluate the genetic diversity within and between switchgrass genotypes [37-39]. Among the different types of markers, sequence-related amplified polymorphism (SRAP) markers are useful because of their reproducibility, low cost, ability to amplify without prior knowledge of the target sequence, and ease of use [40]. SRAP markers have been successfully used to evaluate genetic diversity and to construct genetic maps in species ranging from field crops to forage grasses and tree species [40-43].

Systematically evaluating diverse switchgrass germplasms in response to drought stress will be helpful for identifying genetic resources that can be used to breed elite switchgrass cultivars with improved drought tolerance. Switchgrass germplasms with distinct responses to drought stress will be useful for studying the mechanisms underlying drought tolerance and for identifying genes or molecular markers that can be used for molecular breeding. The objectives of this study were: (1) to determine the morphological, physiological, and metabolic parameters that are important indicators of switchgrass drought tolerance, and (2) to identify drought-tolerant and drought-sensitive switchgrass genotypes from 49 genetically diverse lowland and upland switchgrass genotypes.

\section{Results}

UPGMA clustering analysis to evaluate the genetic background of 49 switchgrass genotypes

Switchgrass has a diverse geographic distribution [8]. Presently, a method for efficient systematic evaluation of diverse switchgrass germplasms for drought tolerance has not yet been reported. In this study, we selected 49 switchgrass genotypes from 49 accessions that include both upland and lowland ecotypes for drought stress evaluation (Table 1). To estimate the genetic diversity of the 49 switchgrass genotypes, we performed SRAP analysis

Table 1 List of switchgrass accessions

\begin{tabular}{|c|c|c|c|c|c|c|c|}
\hline Genotype no. & Accession & Plantid & Ecotype & Genotype no. & Accession & Plantid & Ecotype \\
\hline 1 & PI 421999 & AM-314/MS-155 & Lowland & 26 & PI 414066 & Grenville-2 & Upland \\
\hline 2 & PI 315728 & BN-13645-64 & Lowland & 27 & PI 476292 & T-2100 & Upland \\
\hline 3 & PI 422006 & Alamo & Lowland & 28 & Grif 16407 & Blackwell-1 & Upland \\
\hline 4 & PI 607838 & TEM-SEC & Lowland & 29 & Grif 16409 & Blackwell-2 & Upland \\
\hline 5 & PI 607837 & TEM-SLC & Lowland & 30 & PI 421520 & Blackwell-3 & Upland \\
\hline 6 & PI 636468 & TEM-LoDorm & Lowland & 31 & PI 642192 & Pathfinder & Upland \\
\hline 7 & PI 421521 & Kanlow & Lowland & 32 & PI 549094 & Trailblazer & Upland \\
\hline 8 & PI 476296 & T16971 & Upland & 33 & Grif 16408 & Grif Nebraska 28 & Upland \\
\hline 9 & PI 414070 & BN-12323-69 & Lowland & 34 & Grif 16054 & Central lowa Germplasm & Upland \\
\hline 10 & PI 414068 & BN-18758-67 & Upland & 35 & PI 204907 & Turkey & Upland \\
\hline 11 & PI 476290 & T-2086 & Lowland & 36 & PI 642193 & $70 S G 001$ & Upland \\
\hline 12 & PI 476293 & $\mathrm{~T}-2101$ & Upland & 37 & PI 642194 & $70 S G 002$ & Upland \\
\hline 13 & PI 315727 & $\mathrm{BN}-11357-63$ & Lowland & 38 & PI 642195 & $70 S G 003$ & Upland \\
\hline 14 & PI 642191 & Summer & Upland & 39 & PI 642196 & $70 S G 004$ & Upland \\
\hline 15 & PI 469228 & Cave-in-Rock & Upland & 40 & PI 642197 & 70SG005 & Upland \\
\hline 16 & PI 591824 & Shawnee & Upland & 41 & PI 642207 & $70 S G 0016$ & Upland \\
\hline 17 & PI 476297 & Caddo & Upland & 42 & PI 642208 & $70 S G 0017$ & Upland \\
\hline 18 & PI 478001 & Forestburg & Upland & 43 & PI 642209 & 70SG0018 & Upland \\
\hline 19 & PI 598136 & Sunburst & Upland & 44 & PI 642210 & $70 S G 0019$ & Upland \\
\hline 20 & PI 477003 & Nebraska 28 & Upland & 45 & PI 642211 & $70 S G 0020$ & Upland \\
\hline 21 & PI 537588 & Dacotah & Upland & 46 & PI 642212 & 70SG0021 & Upland \\
\hline 22 & PI 476295 & T4613 & Upland & 47 & PI 642213 & $70 S G 0022$ & Upland \\
\hline 23 & PI 476294 & $\mathrm{~T} 4614$ & Upland & 48 & PI 642214 & $70 S G 0023$ & Upland \\
\hline 24 & PI 315724 & BN-10860-61 & Upland & 49 & PI 642215 & $70 S G 0024$ & Upland \\
\hline 25 & PI 414067 & BN-8624-67 & Upland & & & & \\
\hline
\end{tabular}


Table 2 The number of SRAP fragments generated from 12 primer pair combinations in switchgrass

\begin{tabular}{lccc}
\hline Primer pair & $\begin{array}{l}\text { Total no. } \\
\text { of bands }\end{array}$ & $\begin{array}{l}\text { No. of } \\
\text { polymorphic } \\
\text { bands }\end{array}$ & $\begin{array}{l}\text { Percent } \\
\text { polymorphic } \\
\text { bands (\%) }\end{array}$ \\
\hline me7 + em15 & 14 & 13 & 92.9 \\
me1 + em19 & 14 & 14 & 100.0 \\
me4 + em19 & 10 & 9 & 90.0 \\
me12 + em5 & 9 & 9 & 100.0 \\
me2 + em4 & 19 & 18 & 94.7 \\
me7 + em4 & 11 & 9 & 81.8 \\
me8 + em13 & 16 & 14 & 87.5 \\
me9+em13 & 18 & 17 & 94.4 \\
me11 + em15 & 22 & 22 & 100.0 \\
me12 + em9 & 16 & 16 & 100.0 \\
me3 + em3 & 12 & 10 & 83.3 \\
me5 + em19 & 19 & 16 & 84.2 \\
Total & 180 & 167 & 92.4 \\
\hline
\end{tabular}

using 12 primer pairs (Table 2). The 12 SRAP primer pairs produced a total of 180 DNA markers, of which 167 were polymorphic (representing $92.4 \%$ of all bands). The SRAP data were used for UPGMA cluster analysis (Fig. 1) at a genetic similarity coefficient value of 0.66 . The results of the UPGMA cluster analysis revealed that the 49 genotypes clustered into two groups. Eleven genotypes (AM314/MS-155, BN-13645-64, T16971, TEM-SEC, Alamo, TEM-SLC, TEM-LoDorm, Kanlow, BN-12323-69, Summer, and T-2086) diverged from the others and closely clustered into one group (cluster a). This group included all of the lowland genotypes used in this study (AM-314/ MS-155, BN-13645-64, BN-11357-63, Alamo, TEM-SEC,
TEM-SLC, TEM-LoDorm, T-2086, BN-12323-69, and Kanlow). Interestingly, T16971 and Summer, two upland genotypes, also clustered into the lowland group (cluster a). This could be attributed to the limited number of primers (12 pairs) used for SRAP analysis and/or the close genetic background of these upland and lowland genotypes. The other 38 genotypes that were evaluated in this study clustered together in a second large group (cluster b). Thus, the results of SRAP analysis revealed that the selected 49 genotypes represent a diverse genetic pool of switchgrass germplasm.

\section{Physiological and morphological evaluation of the drought responses of $\mathbf{4 9}$ switchgrass genotypes by heatmap and PCA methods}

We evaluated the 49 switchgrass genotypes for their responses to drought treatment. Drought responses in both well-watered and drought-stressed plants were measured using seven physiological parameters (RWC, EL, Pn, $g_{s}, T r, C i$, and WUE) and four morphological traits [plant height, leaf length (LL), leaf width (LW), and leaf sheath length (SL)]. Our results found that the effects of soil moisture regime and genotype, as well as the interaction between soil moisture and genotype, were significant $(p \leq 0.05)$ for all physiological parameters (Table 3 ). However, for each of the morphological parameters (plant height, LL, LW, and SL), the effects of soil moisture regime and the interaction between soil moisture and genotype were not significant $(p \leq 0.05)$ (Table 3$)$.

To identify the key parameters for assessing drought tolerance in switchgrass, both physiological and morphological measurements were used to plot a heatmap. As shown in Fig. 2, the morphological and physiological

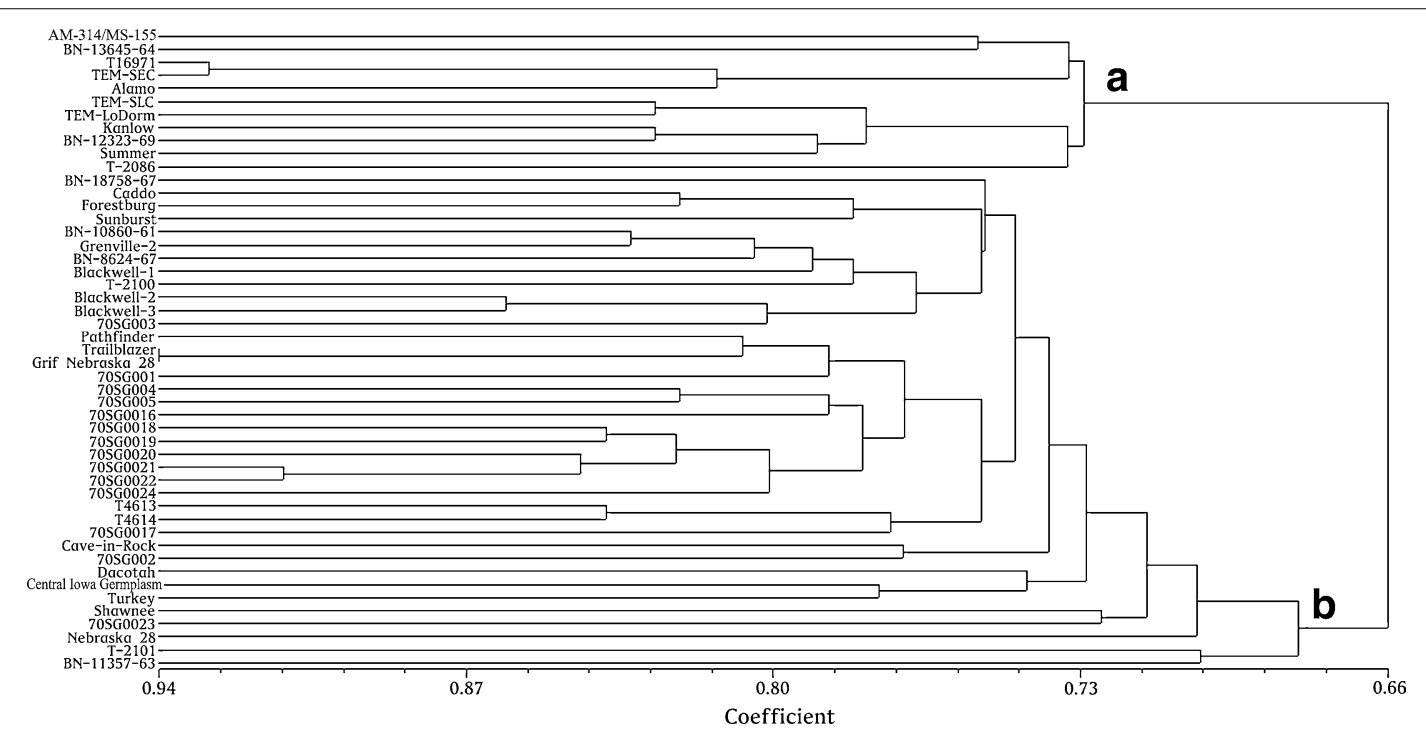

Fig. 1 UPGMA dendrograms of cluster analysis of the 49 switchgrass genotypes based on the similarity coefficients calculated using SRAP data 
Table 3 Summary of analysis of variance for the effects of treatments, lines, and the interaction on leaf relative water content (RWC), electrolyte leakage (EL), photosynthetic rate (Pn), stomatal conductance $\left(g_{s}\right)$, transpiration rate (Tr), intercellular $\mathrm{CO}_{2}$ concentration (Ci), water use efficiency (WUE), leaf length (LL), leaf width (LW) and leaf sheath length (SL) with the data of $\mathbf{3 0}$ days

\begin{tabular}{|c|c|c|c|c|c|c|c|c|c|c|}
\hline Variable & Pn & EL & RWC & $\mathrm{Tr}$ & $g_{\mathrm{s}}$ & WUE & Height & LL & LW & SL \\
\hline Treatment & $* * *$ & $* * *$ & $* * *$ & $* * *$ & $* * *$ & $* * *$ & NS & NS & NS & $*$ \\
\hline Lines & $* *$ & $* *$ & $* *$ & $*$ & * & $*$ & $* * *$ & $* *$ & $*$ & $* *$ \\
\hline Treatment $\times$ lines & * & * & * & * & * & NS & NS & NS & NS & NS \\
\hline
\end{tabular}

** Significant at $P \leq 0.01,{ }^{* * *}$ significant at $P \leq 0.001, N S$ nonsignificant at $P \leq 0.05$

measurements of the 49 genotypes, grown under either drought treatment or well-watered conditions (control), were used for hierarchical (row) clustering. When grown under well-watered conditions, the 49 genotypes clustered into group a while the same set of 49 genotypes grown under drought conditions clustered into group $b$. This clear clustering demonstrates that in comparison to control conditions, drought stress treatment alters both the physiological and morphological characteristics for each switchgrass genotype. Interestingly, most of the lowland genotypes tended to cluster together under wellwatered conditions (group a in Fig. 2, dot-highlighted); however, these genotypes are scattered under drought stress conditions (group b in Fig. 2, dot-highlighted).

To evaluate the contributions of each parameter in the control and drought-treated switchgrass plants, we performed PCA using both physiological (RWC, EL, Pn, $\mathrm{g}_{\mathrm{s}}$, $\mathrm{Tr}, \mathrm{Ci}$, and WUE) and morphological (plant height, LL, LW, and SL) parameters collected from plants after 30 days of drought treatment. The physiological parameters contributed more than the morphological parameters to the separation of the control and drought-treated groups (Fig. 3). Among the seven physiological parameters, Pn, $\mathrm{g}_{\mathrm{s}}, \mathrm{Ci}, \mathrm{Tr}$, and RWC were positively associated with the control treatment (well-watered) group (Fig. 3, circled). WUE and EL were positively correlated with drought treatment (Fig. 3, box). The four morphological traits (plant height, LL, LW, and SL) did not contribute to the separation of the genotypes under either condition. A similar result was found after 15 days of drought treatment (Additional file 1: Figure S1).

Hierarchical clustering analysis of the heatmap also indicated that the physiological and morphological measurements could cluster the 49 genotypes into three distinct groups (top of Fig. 2 group I, II, III). The four morphological measurements, which reflect relative long-term response to abiotic stress, were clustered together (top of Fig. 2, group I) and were not consistently different between the control (Fig. 2, group a) and the short-term drought treatment groups (Fig. 2, group b). Thus, morphological traits do not appear to closely correlate with short-term drought tolerance in switchgrass (Additional file 2: Tables S1, S2).

The four photosynthesis-related traits $\left(\mathrm{Pn}, \mathrm{Tr}, \mathrm{g}_{\mathrm{s}}\right.$, and $\mathrm{Ci}$ ) and RWC were clustered into group II, where all 49 genotypes showed decreased $\mathrm{Pn}, \mathrm{Tr}, \mathrm{g}_{\mathrm{s}}, \mathrm{Ci}$, and RWC under drought treatment (Fig. 2). When the 49 genotypes were evaluated using the drought stress index (DSI), significant differences in the DSI of Pn were observed among the 49 genotypes (Additional file 3: Figure S2). TEM-LoDorm, T2101, TEM-SEC, TEM-SLC, and Alamo all had a higher Pn than the other genotypes under drought stress, resulting in a comparatively higher DSI (>52.0 \%). The upland genotypes, including Central Iowa Germplasm, 70SG001, Dacotah, Nebraska 28, and Grenville-2, had a lower DSI for Pn $(<17.2 \%)$ in comparison to the other genotypes. Drought stress reduced $g_{\mathrm{s}}$ in all 49 genotypes (Additional file 4: Figure S3). The BN-13645-64, TEM-SEC, 70SG0024, BN-10860-61, and TEM-LoDorm genotypes had DSIs for $g_{\mathrm{s}}$ of less than $44.5 \%$. Upland genotypes, including 70SG003, Grif Nebraska 28, Cave-in-Rock, Nebraska 28, and 70SG0016, had somewhat lower DSIs for $g_{s}$, resulting in DSIs less than $14.6 \%$. There were significant differences in the DSI for $\operatorname{Tr}$ among the 49 genotypes (Additional file 5: Figure S4). BN-12323-69, TEM-SEC, BN-10860-61, BN-1364564, and T-2100 had greater DSIs for Tr than the other genotypes. Overall, the Tr DSIs for these genotypes were greater than $45.9 \%$. Alternatively, Grenville-2, Dacotah, Blackwell-3, Central Iowa Germplasm, and 70SG0021 had lower DSI Tr values with DSIs less than $15.3 \%$. There were also significant differences in the DSIs for $\mathrm{Ci}$ among the 49 genotypes (Additional file 6: Figure S5). BN-1875867, Caddo, BN-13645-64, 70SG0019, and TEM-LoDorm had comparatively higher DSIs for $\mathrm{Ci}$, which resulted in DSIs greater than $48.4 \%$. In contrast, 70SG003, Nebraska 28, Grenville-2, Central Iowa Germplasm, and 70SG0016 had relatively lower DSIs for $\mathrm{Ci}$, resulting in DSIs of less than $27.2 \%$ for these genotypes. Drought stress reduced the RWC of all switchgrass genotypes (Additional file 7: Figure S6). The genotypes TEM-LoDorm, BN-12323-69, Alamo, TEM-SEC, and BN-10860-61 all had a DSI higher 


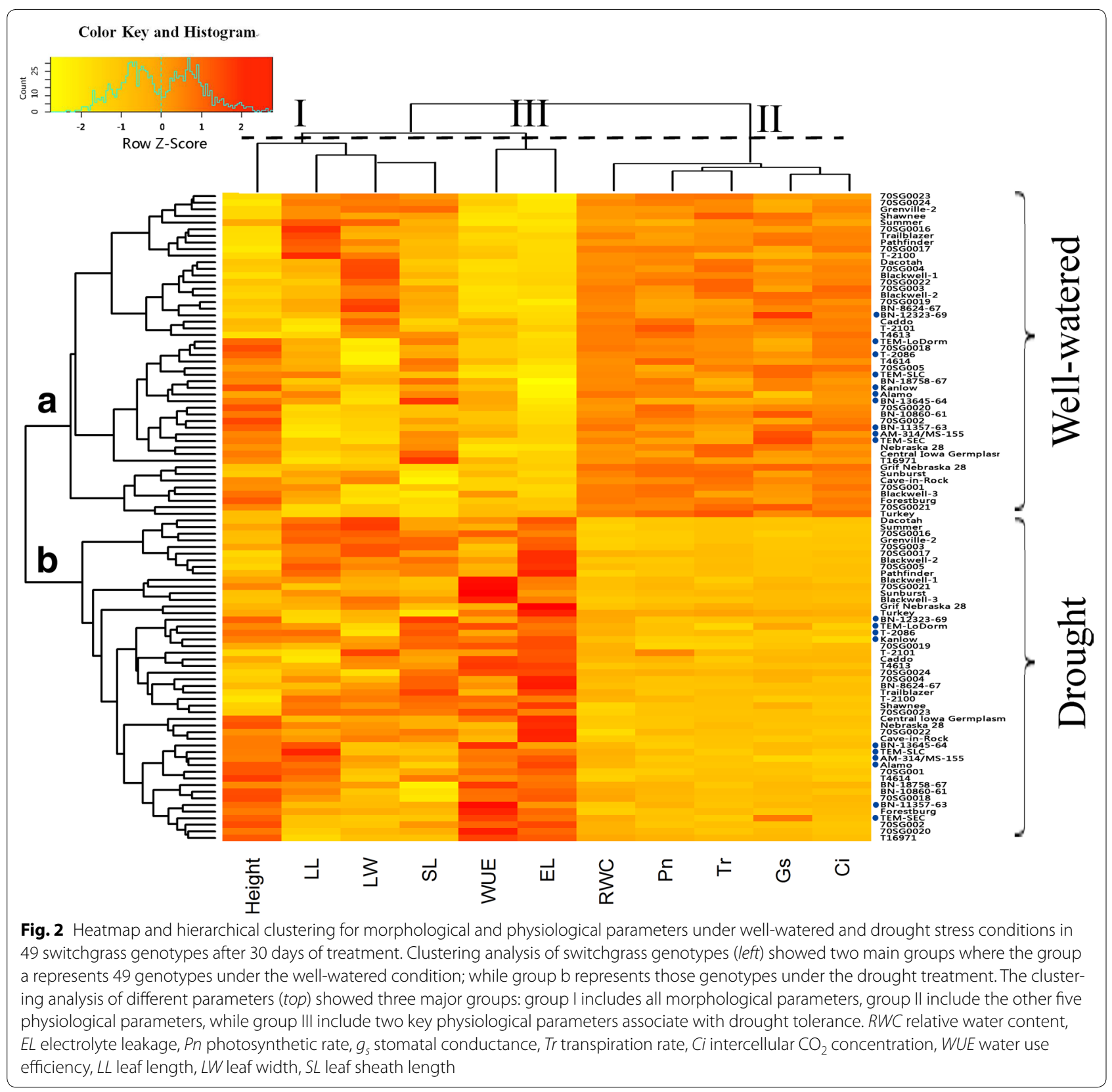

than $70.6 \%$ for RWC. Conversely, the upland genotypes 70SG003, Grif Nebraska 28, 70SG0022, Grenville-2, and Summer all had DSIs lower than 39.3 \% for RWC.

The WUE and EL were clustered into group III (top of Fig. 2). In general, all 49 genotypes showed increased WUE and EL under drought treatment. The WUE is a parameter that is derived from the $\mathrm{Pn}$ and $\mathrm{Tr}$ values. WUE consistently increased under drought treatment in all 49 genotypes, while the EL, a measurement of the damage of cell membrane, consistently increased in all 49 genotypes in response to drought treatment. As shown in Additional file 8: Figure S7, a large variation in WUE was observed. The genotypes Blackwell-3, Forestburg, 70SG0021, Sunburst, and BN-11357-63 tended to have higher DSIs (>187.7 \%) for WUE. Alternatively, the genotypes 70SG0017, Grif Nebraska 28, 70SG003, BN-1232369 , and Pathfinder tended to have relatively lower DSIs (<96.5\%) for WUE. Several lowland genotypes, including BN-13645-64, Alamo, and TEM-SLC, had intermediate WUEs and DSIs ranging from 122.7 to $154.5 \%$. The EL reflects cell membrane damage that occurs during drought stress. In addition, the EL may also affect $\mathrm{Tr}$ and Pn (and subsequently affect WUE). Drought stress resulted in an increased EL for all genotypes (Additional 


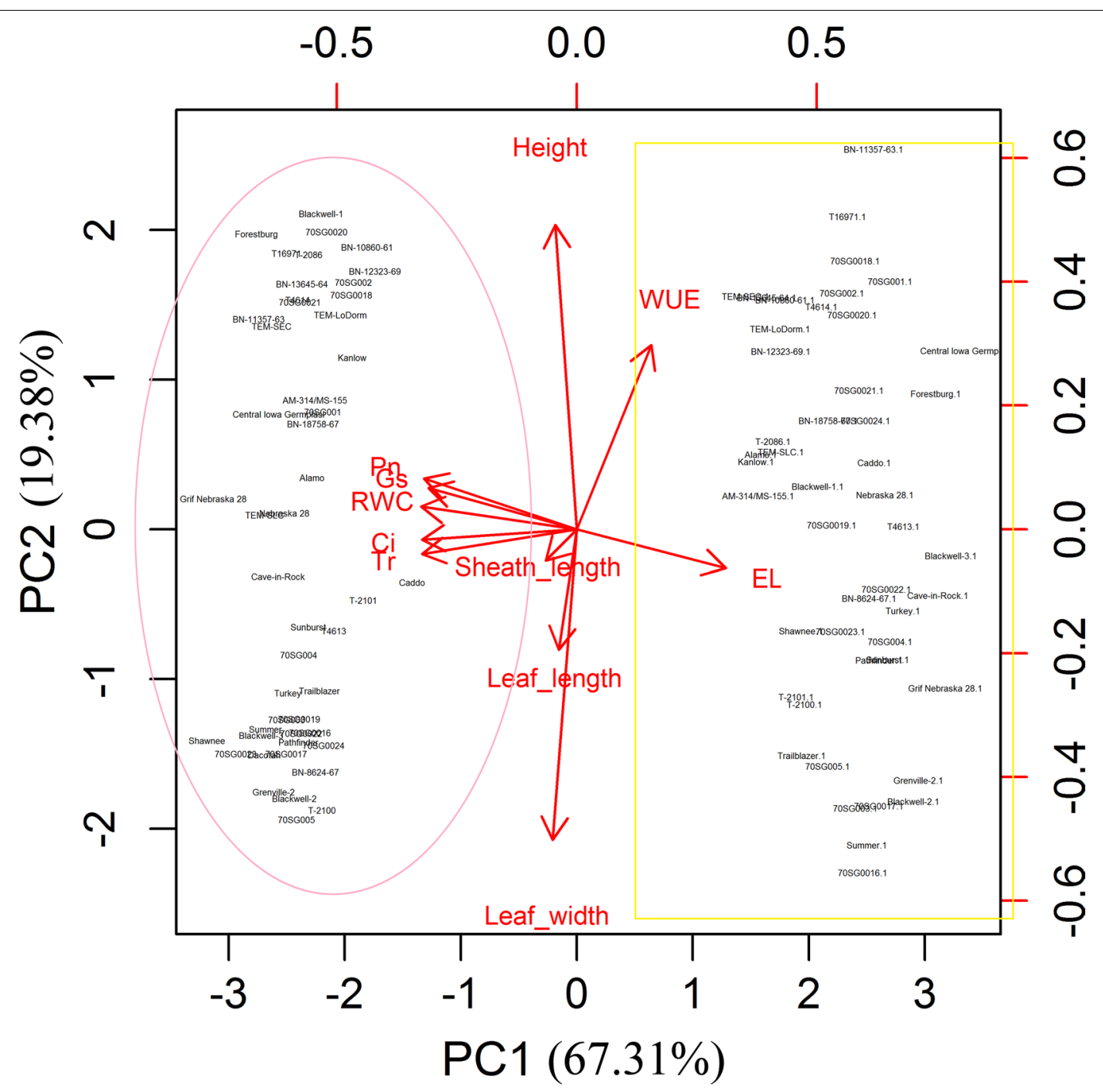

Fig. 3 Principal component analysis biplot of morphological and physiological traits of 49 switchgrass genotypes under well-watered and drought stress conditions after 30 days of treatment. The seven physiological parameters (Pn, Ci, $g_{s^{\prime}}, \mathrm{Tr}, \mathrm{RWC}, \mathrm{WUE}$ and EL) allow to separate 49 switchgrass genotypes that were either grown under well-watered (circled) or drought treatment (box) conditions. Arrows represent physiological traits with various length based on the impact of each trait on the separation of genotypes. RWC relative water content, EL electrolyte leakage, Pn photosynthetic rate, $g_{s}$ stomatal conductance, $\operatorname{Tr}$ transpiration rate, $C i$ intercellular $\mathrm{CO}_{2}$ concentration, WUE water use efficiency, $L L$ leaf length, LW leaf width, $S L$ leaf sheath length

file 9: Figure S8). The genotypes TEM-SEC, T4614, BN-11357-63, BN-13645-64, and T-2086 all had relatively lower DSIs $(<173.7 \%)$ for the EL values in comparison to the other genotypes. Overall, all 49 genotypes showed increased WUE and EL under drought treatment.

The 49 switchgrass genotypes can be clustered into three groups based on DSI values for seven physiological measurements at $\mathbf{3 0}$ days of drought treatment

Heatmap hierarchical clustering and PCA indicated that physiological parameters are important for distinguishing the control and drought treatments in switchgrass. To cluster the switchgrass genotypes that had similar physiological responses to drought, we performed PCA using the DSI of seven physiological measurements collected at 30 days of drought treatment. The results of this PCA analysis identified three major groups (group I, II and III) (Fig. 4). In general, the lowland genotypes clustered mainly into groups I and II; however, upland genotypes such as BN-1086061, T-2100, T-2101, Caddo, and BN-18758-67 also clustered in groups I and II. This suggests that these upland genotypes have similar tolerance to drought as their lowland counterparts. 


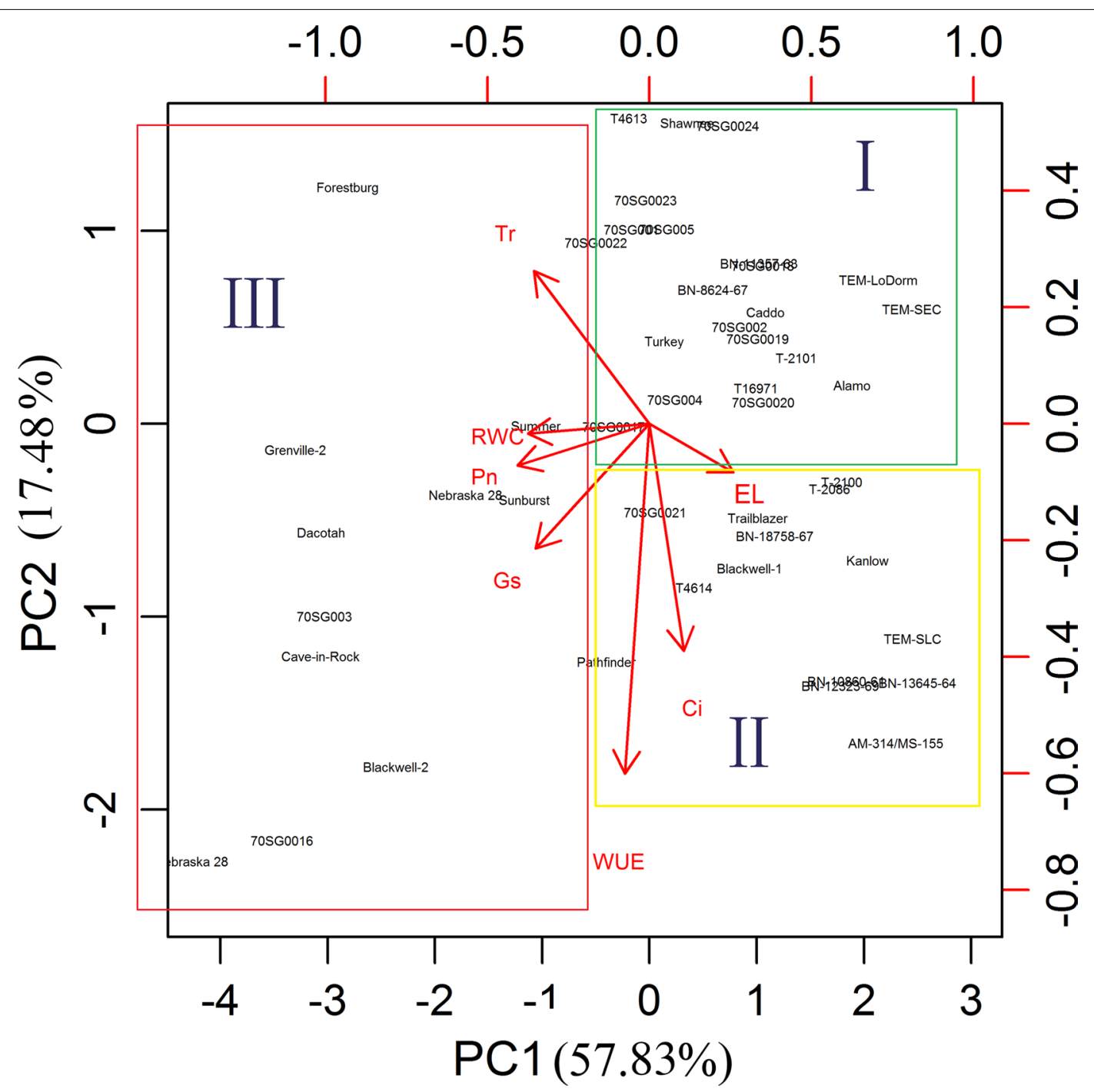

Fig. 4 Principal component analysis biplot of the DSI of seven physiological traits of 49 switchgrass genotypes under well-watered (control) and drought stress conditions after 30 days of treatment. Arrows represent physiological traits with various length based on the impact of each trait on the separation of genotypes. The 49 switchgrass genotypes were clustered into three major groups. Group I include switchgrass genotypes that have the best performance based on DSI of the physiological parameters, while group III genotypes have the worst performance, and group II include the intermediate genotypes. The proportion of variance for principal component analysis based on the DSI of seven physiological traits is shown in Additional file 10: Figure S9, where it suggested the top two PCs can explain $75.31 \%$ of total variation. RWC relative water content, EL electrolyte leakage, $P n$ photosynthetic rate, $g_{s}$ stomatal conductance, $\operatorname{Tr}$ transpiration rate, $C i$ intercellular $\mathrm{CO}_{2}$ concentration, WUE water use efficiency

PCA using the DSI values of seven physiological measurements collected at 30 days also suggests that the first principal component (PC1) explained approximately $57.83 \%$ of the variance in the data and that the second (PC2) and third components (PC3) explained an additional 17.48 and $12.22 \%$ of the variance, respectively. Together, the three components (PC1, PC2, and PC3) could explain $87.53 \%$ of the variance among the 49 genotypes (Additional file 10: Figure S9). Because of the importance of physiological parameters for distinguishing the control and drought treatments in switchgrass, the relationships among the seven physiological parameters were further analyzed. We performed correlation analysis using Pearson's method. Table 4 shows that under drought stress, the correlations of Pn with EL, RWC, Tr, $g_{\mathrm{s}}$, and WUE were significant $(p<0.05)$ because they had large correlation coefficients $(r)$ of $-0.549,0.555,0.766,0.737$ and 0.847 , respectively. These findings reveal that these physiological indicators, particularly $\mathrm{Pn}$, are important parameters for assessing tolerance to abiotic stresses, including drought. 
Table 4 The correlation coefficient ( $r$ ) between physiological measurements in 49 switchgrass genotypes under drought stress

\begin{tabular}{|c|c|c|c|c|c|c|}
\hline & Pn & $\mathrm{EL}$ & RWC & $\mathrm{Tr}$ & $g_{\mathrm{s}}$ & WUE \\
\hline $\mathrm{Pn}$ & 1 & $-0.549^{* * *}$ & $0.555^{* *}$ & $0.766^{* * *}$ & $0.737^{* * *}$ & $0.847^{* * *}$ \\
\hline EL & & 1 & -0.188 & $-0.309^{*}$ & $-0.369^{* *}$ & $-0.456^{* *}$ \\
\hline RWC & & & 1 & $0.525^{* *}$ & $0.536^{* * *}$ & $0.421^{* *}$ \\
\hline $\operatorname{Tr}$ & & & & 1 & $0.674^{* * *}$ & $0.472^{* *}$ \\
\hline$g_{\mathrm{s}}$ & & & & & 1 & $0.511^{* *}$ \\
\hline WUE & & & & & & 1 \\
\hline
\end{tabular}

$*, * *$ and ${ }^{* * *}$ indicate significance at the $0.05,0.01$, and 0.001 levels, respectively $(n=49)$

\section{Drought tolerance ranking of the $\mathbf{4 9}$ switchgrass genotypes using integrated PCA values}

Since the PCA that was based on the DSI of seven physiological parameters (Fig. 4; Additional file 10: Figure S9) showed that three major components (PC1, PC2, and PC3) could explain $87.53 \%$ of the variance in response to drought treatment (Additional file 10: Figure S9), we developed the following formulas based on the results of PCA: (1) PC1 $=0.926 \times \mathrm{RWC}+0.957 \times \mathrm{Pn}+0.938 \times$ $\mathrm{Tr}+0.907 \times g_{\mathrm{s}}+(-0.372) \times \mathrm{Ci}+(-0.109) \times \mathrm{WUE}+($ $-0.649) \times \mathrm{EL} ;(2) \mathrm{PC} 2=0.0034 \times \mathrm{RWC}+0.134 \times \mathrm{Pn}$ $+(-0.205) \times \mathrm{Tr}+0.191 \times g_{\mathrm{s}}+0.5144 \times \mathrm{Ci}+0.888 \times$ $\mathrm{WUE}+(-0.2719) \times \mathrm{EL}$; and $(3) \mathrm{PC} 3=0.06428 \times \mathrm{RWC}$ $+0.0089 \times \mathrm{Pn}+0.1597 \times \mathrm{Tr}+0.224 \times g_{\mathrm{s}}+0.752 \times \mathrm{Ci}$ $+(-0.363) \times \mathrm{WUE}+0.2787 \times$ EL. In addition, a ranking value for each switchgrass genotype was calculated using a separate formula [(Ranking value $=(57.83 \% \times$ $\mathrm{PC} 1)+(17.48 \% \times \mathrm{PC} 2)+(12.22 \% \times \mathrm{PC} 3)]$ [44]. The 49 switchgrass genotypes were then ranked for relative drought tolerance. Genotypes TEM-SEC, TEM-LoDorm, BN-13645-64, Alamo, BN-10860-61, BN-12323-69, TEM-SLC, T-2086, T-2100, T-2101, Caddo, and Blackwell-1 had relatively higher ranking values, suggesting that they were more drought tolerant (Table 5). In contrast, genotypes including Grif Nebraska 28, Grenville-2, Central Iowa Germplasm, Cave-in-Rock, Dacotah, and Nebraska 28 had relatively lower ranking values and thus, were found to be more sensitive to drought stress.

\section{Different metabolic responses of the five best drought-tolerant genotypes and the five most drought-sensitive genotypes}

To examine if metabolic responses varied under drought stress, we selected the five most drought-tolerant genotypes (top $10 \%$ genotypes) and the five most droughtsensitive genotypes (bottom $10 \%$ genotypes) for metabolite profiling (Table 5). The levels of 14 metabolites, including ABA, JA, JA-Ile, betaine, proline, putrescine, spermine, spermidine, fructose, glucose, inositol, sucrose, trehalose, and raffinose were analyzed. Among the 14 metabolites, differences in ABA, spermine, trehalose, and fructose were found between the five best drought-tolerant genotypes and the five most droughtsensitive genotypes (Fig. 5). In general, the five best drought-tolerant genotypes tended to accumulate higher levels of ABA, spermine, trehalose, and fructose under drought stress than the five most drought-sensitive genotypes (Fig. 5).

\section{Discussion}

Evaluation of switchgrass germplasm with different physiological and metabolic parameters

In this study, we screened 49 diverse switchgrass genotypes for their tolerance to drought stress by measuring physiological, morphological, and metabolic traits. Our results indicate that the physiological parameters contributed more than the morphological traits in separating the control and drought-treated groups. This suggests that physiological characteristics may be closely associated with short-term drought tolerance in switchgrass. Previously, the evaluation of plant drought tolerance has been complicated due to inconsistencies in testing environments, the interactions between different developmental stages of plant growth, and the handling of a large number of plant genotypes [45]. Thus, no comprehensive, standardized system for measuring drought resistance has been established [46]. Indices that are based on yield loss under drought conditions, in comparison with normal conditions, have been used in crop breeding programs; however, these indices are labor intensive and time consuming $[47,48]$. In this study, we measured a set of physiological parameters under drought treatment to effectively classify a relatively large collection of switchgrass germplasm. This process is non-destructive and sensitive to in planta conditions, which makes it favorable for collecting more reliable drought-related data.

Drought stress significantly altered the physiological parameters (Pn, $g_{s}$, Tr, Ci, and WUE) of all 49 switchgrass genotypes (Additional file 3: Figure S2; Additional file 4: Figure S3; Additional file 5: Figure S4; Additional file 6: Figure S5; Additional file 7: Figure S6; Additional file 8: Figure S7; Additional file 9: Figure S8). During 
Table 5 The three major components (PC1, PC2 and PC3) and PCA ranking values of the physiological parameters of 49 switchgrass lines after $\mathbf{3 0}$ days of drought stress

\begin{tabular}{|c|c|c|c|c|c|}
\hline & PC1 & PC2 & PC3 & Ranking & Numeric rank \\
\hline TEM-SEC & 87.49 & 107.57 & 11.85 & 70.85 & 1 \\
\hline TEM-LoDorm & 63.25 & 104.99 & 13.33 & 56.56 & 2 \\
\hline BN-13645-64 & 69.79 & 71.30 & 26.84 & 56.10 & 3 \\
\hline Alamo & 69.12 & 68.30 & 26.50 & 55.15 & 4 \\
\hline BN-10860-61 & 65.49 & 44.07 & 38.37 & 50.26 & 5 \\
\hline BN-12323-69 & 66.67 & 36.81 & 40.43 & 49.93 & 6 \\
\hline TEM-SLC & 53.58 & 95.92 & 14.45 & 49.52 & 7 \\
\hline T-2086 & 58.96 & 63.42 & 26.55 & 48.43 & 8 \\
\hline T-2100 & 55.28 & 73.88 & 23.46 & 47.75 & 9 \\
\hline T-2101 & 47.80 & 62.32 & 28.42 & 42.01 & 10 \\
\hline Caddo & 43.77 & 73.18 & 24.35 & 41.08 & 11 \\
\hline Blackwell-1 & 30.59 & 94.67 & 15.16 & 36.09 & 12 \\
\hline AM-314/MS-155 & 37.03 & 46.80 & 35.42 & 33.92 & 13 \\
\hline 70SG0019 & 23.45 & 64.54 & 25.49 & 27.96 & 14 \\
\hline 70SG002 & 20.92 & 66.75 & 27.10 & 27.08 & 15 \\
\hline 70SG0018 & 16.78 & 88.39 & 15.72 & 27.08 & 16 \\
\hline T16971 & 19.83 & 68.11 & 25.15 & 26.45 & 17 \\
\hline 70SG0020 & 18.83 & 62.76 & 31.20 & 25.67 & 18 \\
\hline Trailblazer & 23.00 & 43.38 & 34.70 & 25.13 & 19 \\
\hline BN-18758-67 & 17.86 & 60.66 & 32.70 & 24.93 & 20 \\
\hline BN-11357-63 & 5.73 & 128.58 & -7.83 & 24.83 & 21 \\
\hline 70SG0024 & 11.93 & 77.78 & 27.98 & 23.91 & 22 \\
\hline Forestburg & -19.99 & 168.44 & -20.14 & 15.42 & 23 \\
\hline T4614 & 6.53 & 49.47 & 24.46 & 15.41 & 24 \\
\hline Sunburst & -15.56 & 140.08 & -7.26 & 14.60 & 25 \\
\hline Kanlow & 1.36 & 45.30 & 33.07 & 12.75 & 26 \\
\hline Shawnee & -12.10 & 104.59 & 10.56 & 12.57 & 27 \\
\hline BN-8624-67 & -7.92 & 71.94 & 28.49 & 11.48 & 28 \\
\hline Turkey & -16.46 & 72.55 & 21.53 & 5.79 & 29 \\
\hline $70 S G 0023$ & -23.86 & 74.50 & 19.51 & 1.61 & 30 \\
\hline Pathfinder & -16.00 & 36.80 & 30.91 & 0.96 & 31 \\
\hline 70SG005 & -26.21 & 54.68 & 36.22 & -1.17 & 32 \\
\hline T4613 & -34.79 & 88.37 & 22.77 & -1.89 & 33 \\
\hline $70 S G 0021$ & -50.75 & 149.10 & -12.89 & -4.86 & 34 \\
\hline 70SG004 & -34.57 & 41.19 & 47.56 & -6.98 & 35 \\
\hline Blackwell-3 & -68.04 & 189.88 & -33.62 & -10.27 & 36 \\
\hline Summer & -42.97 & 54.36 & 30.46 & -11.63 & 37 \\
\hline 70SG001 & -49.36 & 88.38 & 11.94 & -11.64 & 38 \\
\hline $70 S G 0022$ & -56.64 & 62.00 & 33.21 & -17.86 & 39 \\
\hline 70SG0016 & -64.46 & 84.77 & 8.47 & -21.43 & 40 \\
\hline 70SG0017 & -57.00 & 5.22 & 56.18 & -25.19 & 41 \\
\hline 70SG003 & -58.65 & 23.10 & 34.46 & -25.67 & 42 \\
\hline Blackwell-2 & -65.66 & 49.15 & 29.41 & -25.79 & 43 \\
\hline Grif Nebraska 28 & -63.46 & 15.19 & 40.02 & -29.15 & 44 \\
\hline Grenville-2 & -83.49 & 59.64 & 22.98 & -35.05 & 45 \\
\hline $\begin{array}{l}\text { Central lowa } \\
\text { Germplasm }\end{array}$ & -96.63 & 103.35 & 8.59 & -36.76 & 46 \\
\hline Cave-in-Rock & -85.49 & 34.09 & 34.85 & -39.22 & 47 \\
\hline
\end{tabular}

Table 5 continued

\begin{tabular}{llllll}
\hline & PC1 & PC2 & PC3 & Ranking & Numeric rank \\
\hline Dacotah & -101.37 & 86.86 & 16.36 & -41.44 & 48 \\
Nebraska 28 & -102.90 & 17.87 & 44.40 & -50.96 & 49 \\
\hline
\end{tabular}

drought conditions, the Pn may be inhibited due to stomatal closure. This could inhibit RuBisco activity and increase respiration rates, ultimately leading to depleted carbohydrate reserves, reduced growth rates, and early plant senescence. In response to water deficit, the stomata may also close to conserve water; however, stomatal closure (lower $g_{\mathrm{s}}$ ) may block gas exchange and result in an increase in the $\mathrm{O}_{2} / \mathrm{CO}_{2}$ ratio. With an increase in excess $\mathrm{O}_{2}$ molecules, energy may be directed to them and the production of toxic reactive oxygen species (ROS) becomes a concern $[49,50]$. In turn, these ROS may destroy important cellular components such as proteins, lipids, and nucleic acids, resulting in cell membrane damage (increased EL). Excess ROS may also damage components of the photosynthesis system, reducing the Pn and leaf RWC (Additional file 7: Figure S6) and increasing EL (Additional file 9: Figure S8) [51]. In order to cope with abiotic stresses, such as drought, plants have evolved the ability to evoke antioxidant defense systems, osmotic adjustments, and hormonal regulations of stomatal functions $[17,18]$.

The DSIs for each physiological parameter (Additional file 3: Figure S2; Additional file 4: Figure S3; Additional file 5: Figure S4; Additional file 6: Figure S5; Additional file 7: Figure S6; Additional file 8: Figure S7; Additional file 9: Figure S8) were used to evaluate the relative drought tolerance of all 49 switchgrass genotypes. Our results showed that the drought-tolerant genotypes had higher RWC, $g_{s}$, Pn, Tr, and $\mathrm{Ci}$, and a lower EL than the drought-sensitive genotypes. In addition, the five best drought-tolerant genotypes tended to accumulate higher levels of $\mathrm{ABA}$, spermine, fructose, and trehalose under drought stress than the five most drought-sensitive genotypes (Fig. 5). It has been well documented that ABA induces stomatal closure and reduces water loss through transpiration [23]. Our results show that the drought-tolerant genotypes had higher levels of ABA, $g_{s}$, and $\mathrm{Tr}$, suggesting that these genotypes may achieve a higher tolerance to drought stress by maintaining better gas exchange (high $g_{s}$ and Tr). This high level of gas exchange would reduce ROS toxicity, providing stronger signal-mediated regulations (Fig. 5, higher ABA, spermine, and trehalose) and osmotic adjustments (higher levels of trehalose and fructose). Fructose and trehalose are important osmoprotectants that facilitate osmotic adjustment. A previous study in Arabidopsis also showed 

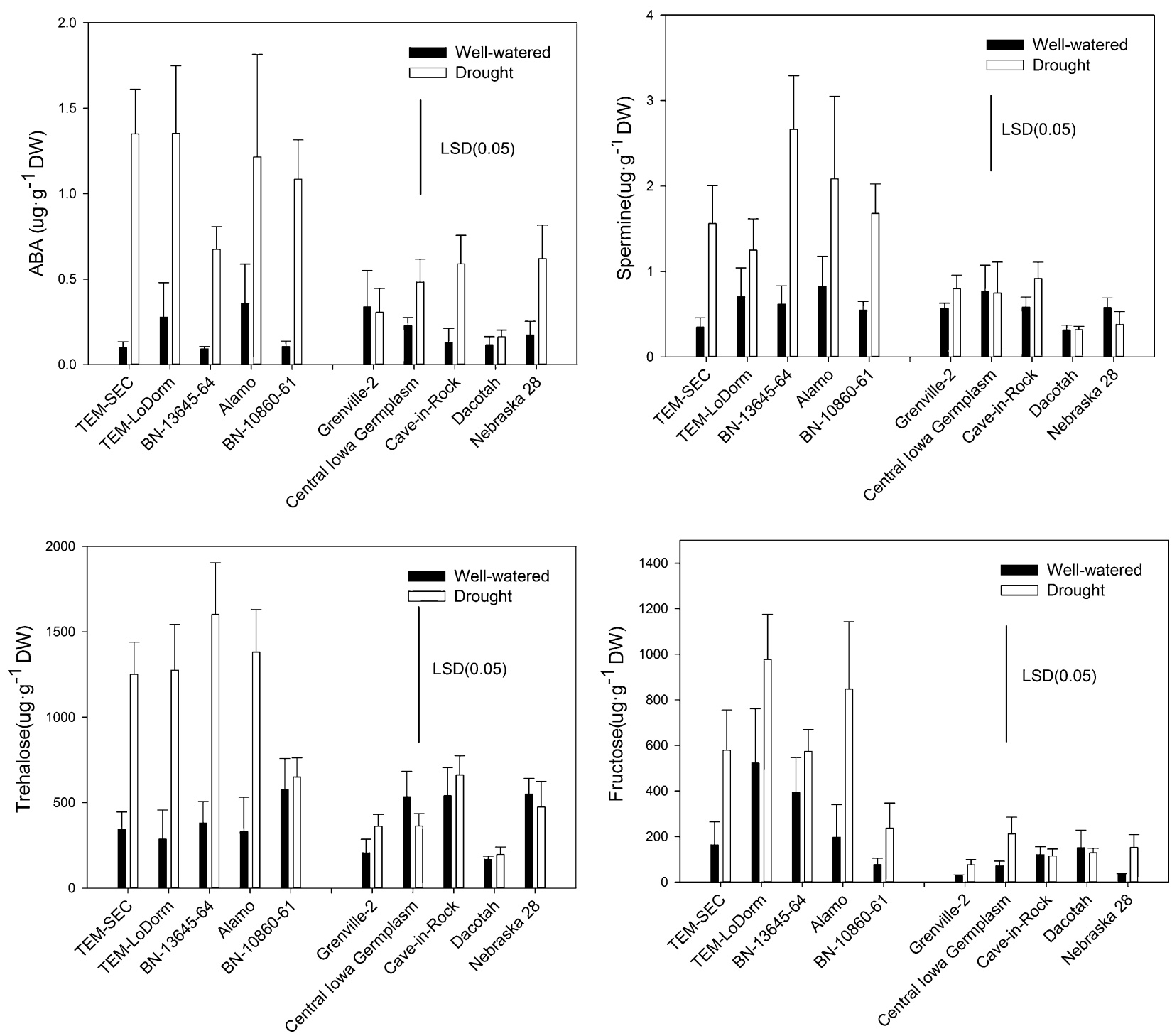

Fig. 5 The levels of abscisic acid (ABA), spermine, trehalose, and fructose in five best drought-tolerant genotypes and the five most drought-sensitive genotypes under well-watered conditions (control, solid bar) and drought stress (open bar) after 30 days of treatment. The values are the means of six replicates $(n=6)$. The bar represents LSD (0.05) for levels of abscisic acid (ABA), spermine, trehalose, and fructose

that spermine is closely correlated with drought tolerance [52]. No consistent differences in any of the other metabolites between drought-tolerant and drought-sensitive genotypes were found in our study. In addition to regulating gas exchange, plants possess various antioxidant metabolites and enzymes to remove ROS. Stomatal functions and photosynthesis efficiency rates under drought conditions may not only be regulated by hormones, such as ABA. The integrity of these processes could also be maintained by other metabolites that might facilitate such harsh osmotic adjustments, ultimately improving drought tolerance in plants $[23,53]$.
Drought-tolerant genotypes have also been shown to have a higher photosynthetic function (higher Pn) relative to drought-sensitive genotypes. Similar results were also found in switchgrass [4], maize [54], and creeping bentgrass [55] under drought treatment. Mohamed [11] found that water stress affected several switchgrass cultivars (Carthage, Alamo, Kanlow, Southlow, Cavein-Rock, Forestburg, Blackwell, Nebraska 28, Shelter, Shawnee, Dacotah, Sunburst, and WI) physiologically by decreasing photosynthesis. Jiang et al. [4] evaluated the upland switchgrass cultivar Cave-in-Rock and noted that drought stress reduced tissue water content, leaf dry 
weight, and chlorophyll fluorescence but increased total carotenoid concentration and EL.

\section{Methods for analysis of large physiological datasets}

It is still challenging to reliably analyze and interpret large physiological datasets collected from plants grown under drought and well-watered conditions. Various methods and statistical models have been proposed for such analyses. Correlation analysis, PCA, and clustering are considered to be good methods for evaluating the relationships between the parameters and their principal components in phenotypic screening for drought tolerance [21, 47, 48]. In this study, PCA and correlation analysis showed that the differences in drought tolerance among the 49 switchgrass genotypes were largely due to variations in physiological parameters, especially Pn (Table 4; Fig. 4). Our results also found that some lowland genotypes, such as TEM-SEC, TEM-LoDorm, BN-13645-64, Alamo, and TEM-SLC, have relatively good tolerance to drought. These genotypes maintain higher $\mathrm{Pn}, \mathrm{Tr}, \mathrm{g}_{\mathrm{s}}, \mathrm{Ci}$, and RWC and lower EL in comparison to the upland genotypes (Additional file 3: Figure S2; Additional file 4: Figure S3; Additional file 5: Figure S4; Additional file 6: Figure S5; Additional file 7: Figure S6; Additional file 9: Figure S8; Table 5). Although the upland genotypes had a comparatively greater WUE than the lowland genotypes, our data showed that WUE was highly variable (Additional file 8: Figure S7). In fact, WUE alone may not be enough of a factor for evaluating drought tolerance [56].

A heatmap is a visual method that can be used to explore complex associations between multiple parameters collected from various treatments. It is often useful to combine heatmap with hierarchical clustering, which is a way of arranging items in a hierarchy based on the distance or similarity between them. Despite its benefits, heatmap analysis (Fig. 2) could not clearly identify the significant differences between the genotypes in this study. PCA biplots (Figs. 3, 4), however, could show the relative contributions of the parameters to the clustered groups. In our study, the PCA based on the DSI of seven physiological parameters yielded three PCs that accounted for $87.53 \%$ of the total variance (Fig. 4; Additional file 10: Figure S9). For the purpose of evaluating switchgrass tolerance to drought stress, the three PCs were sufficient to represent the seven physiological parameters. To comprehensively evaluate the relative drought tolerance of the 49 switchgrass genotypes, a ranking value was calculated for each of the genotypes analyzed in this study (Table 5). Based on their ranking values, genotypes TEM-SEC, TEM-LoDorm, BN-1364564, Alamo, BN-10860-61, BN-12323-69, TEM-SLC, T-2086, T-2100, T-2101, Caddo, and Blackwell-1 were more tolerant to drought stress. In contrast, genotypes
Grif Nebraska 28, Grenville-2, Central Iowa Germplasm, Cave-in-Rock, Dacotah, and Nebraska 28 were relatively sensitive to drought stress.

\section{Conclusion}

There is wide variation in the drought tolerance of the 49 switchgrass genotypes examined in this study. Based on DSI values for each physiological parameter, cluster analysis, and PCA ranking, we found that genotypes TEM-SEC, TEM-LoDorm, BN-13645-64, Alamo, BN-10860-61, BN-12323-69, TEM-SLC, T-2086, T-2100, T-2101, Caddo, and Blackwell-1 were more drought tolerant. We also found that genotypes Grif Nebraska 28, Grenville-2, Central Iowa Germplasm, Cave-in-Rock, Dacotah, and Nebraska 28 were relatively sensitive to drought stress. The physiological measurements and metabolic profiles generated in this study offered a sensitive, reliable approach for identifying switchgrass genotypes that are tolerant or sensitive to drought stress. The results of this study provide a foundation for further investigating the molecular mechanisms underlying switchgrass tolerance to drought stress.

\section{Methods}

\section{Plant materials and culture}

This study was performed in a greenhouse at Virginia Tech (Blacksburg, VA, USA). Diverse switchgrass germplasm accessions were originally obtained from the United States Department of Agriculture Germplasm Center and were maintained in the Virginia Tech Kentland Farm Agricultural Station (Blacksburg, VA, USA). One genotype from each of the 49 switchgrass accessions was chosen for this study (Table 1). Each switchgrass genotype was propagated by splitting tillers. On May 12, 2012, a tiller from each genotype was planted in a large pot (40 cm diam., $45 \mathrm{~cm}$ deep) filled with $12 \mathrm{~kg}$ of a mixture of sandy loam top soil and sand $(2: 1, \mathrm{v} / \mathrm{v}$, 0.1-1.0 mm diam.). After 2 months of culture, six tillers from each genotype were transplanted into six plastic pots $(17 \mathrm{~cm}$ diam., $20 \mathrm{~cm}$ high, with four holes at the bottom for drainage) and filled with $3.5 \mathrm{~kg}$ of a soil and sand mixture (soil:sand $=2: 1 \mathrm{v} / \mathrm{v}$, sand: $0.1-1.0 \mathrm{~mm}$ diam.). Of the 49 genotypes (Table 1), ten (AM-314/MS-155, BN-13645-64, BN-11357-63, Alamo, TEM-SEC, TEMSLC, TEM-LoDorm, T-2086, BN-12323-69, and Kanlow) were lowland ecotypes $[8,57]$, and the rest were upland ecotypes.

The plants were grown in the greenhouse at temperatures of $30 \pm 1{ }^{\circ} \mathrm{C} / 25 \pm 1{ }^{\circ} \mathrm{C}$ (day/night), a 14-h photoperiod, $75 \%$ relative humidity, and with photosynthetically active radiation of approximately $500 \mu \mathrm{mol} \mathrm{m}^{-2} \mathrm{~s}^{-1}$ (natural daylight supplemented with fluorescent lamps). The plants were irrigated daily, and fertilizer containing $\mathrm{N}$ 
(Bulldog brand, 28-8-18, $1 \%$ ammonia N, $4.8 \%$ nitrate $\mathrm{N}$, and $22.2 \%$ urea N; SQM North America, Atlanta, GA, USA) and micronutrients was applied at $0.49 \mathrm{~kg} \mathrm{~m}^{-2}$ every week.

\section{Drought stress treatment}

After the plants were grown for 2 months (Sep 10, 2012) and had reached the E5 developmental stage [58], they were exposed to one of two soil moisture treatments (well-watered or drought stress) for 30 days.

The plants from each genotype were randomly assigned to either the control group $(n=6)$, which was kept well watered to maintain the soil moisture content at container capacity, or to the drought treatment group $(n=6)$, in which the soil moisture was allowed to gradually decline from day 0 to day 30 by reducing the amount of water used for irrigation. Water was added daily to compensate for 30-50 \% ET loss during the experiment over the 30-day period. ET was determined by weighing the pots [59]. In addition, the volumetric soil moisture content (VWC) was monitored using a soil moisture meter (model HH2, Delta-T Devices, Cambridge, England).

In a separate experiment, the soil water content (SWC) of the growth media was determined based on differences in soil sample weight before and after drying at $105^{\circ} \mathrm{C}$ to a constant weight. This difference was expressed as the percentage of the weight lost relative to the oven-dried weight. Soil samples were taken at different time points and each data point is the average of the measurements.

On average, the volumetric water content (VWC) was reduced from 40.00 to $21.24 \%$ and the SWC was reduced from 26.21 to $17.34 \%$ between days 0 and 15 . Between days 15 and 25, the VWC was reduced from 21.24 to $10.94 \%$ and the SWC was reduced from 17.34 to $8.09 \%$. Finally, the VWC was reduced from 10.94 to $5.79 \%$ and the SWC was reduced from 8.09 to $4.31 \%$ between days
25 and 30. The well-watered pots were irrigated daily to maintain approximately $40.0 \%$ volumetric soil moisture (Table 6). The amount of water given each day was determined according to ET [59].

\section{Physiological measurements}

To measure electrolyte leakage (EL) and relative water content (RWC), leaf samples were collected after 0, 5, $10,15,20,25$, and 30 days of drought stress. At the same time points, the photosynthetic rate $(\mathrm{Pn})$, stomatal conductance $\left(g_{\mathrm{s}}\right)$, intercellular $\mathrm{CO}_{2}$ concentration $(\mathrm{Ci})$, and transpiration rate $(\mathrm{Tr})$ were determined. At the end of the experiment (30 days), leaf tissue samples for metabolite and genetic diversity analyses were collected and frozen in liquid $\mathrm{N}_{2}$.

Leaf electrolyte leakage (EL) was measured according to the method of Marcum [60] with some modifications. The top 2nd or 3rd mature leaf blades were excised and cut into 2-cm segments. After rinsing 3 times with deionized $\mathrm{H}_{2} \mathrm{O}, 0.2 \mathrm{~g}$ of the leaf tissue was placed in a $50-\mathrm{mL}$ test tube containing $20 \mathrm{~mL}$ deionized $\mathrm{H}_{2} \mathrm{O}$. The test tubes were agitated on a shaker for approximately $24 \mathrm{~h}$, and the solution conductivity $\left(C_{1}\right)$ was measured with a conductivity meter (SR60IC, VWR, Radnor, PA, USA). The leaf samples were then autoclaved at $120{ }^{\circ} \mathrm{C}$ for $30 \mathrm{~min}$, and when the tubes cooled to room temperature, the conductivity of the solution containing the killed tissue was measured $\left(C_{2}\right)$. The relative EL was calculated using the formula: $\mathrm{EL}(\%)=\left(C_{1} / C_{2}\right) \times 100$.

Leaf relative water content (RWC) was determined according to the method of Barrs and Weatherley and was based on the following formula: RWC $=(F W-D W) /$ $(T W-D W) \times 100$, where FW is leaf fresh weight, DW (dry weight) is the weight of the leaves after drying at $85^{\circ} \mathrm{C}$ for 3 days, and TW (turgid weight) is the weight of the leaves after soaking them in distilled water for $24 \mathrm{~h}$ at $20{ }^{\circ} \mathrm{C}$.

Table 6 The change in soil volumetric water content and soil water content over time in well-watered and drought conditions

\begin{tabular}{|c|c|c|c|c|c|c|}
\hline \multirow[t]{2}{*}{ Day } & \multicolumn{3}{|c|}{ well-watered } & \multicolumn{3}{|c|}{ Drought } \\
\hline & ET (\%) & VWC (\%) & SWC (\%) & ET (\%) & VWC (\%) & SWC (\%) \\
\hline 0 & 100 & $40.2 \pm 1.70$ & $26.3 \pm 1.04$ & 100 & $40.0 \pm 2.23$ & $26.2 \pm 2.40$ \\
\hline 5 & 100 & $39.8 \pm 1.35$ & $27.1 \pm 1.82$ & 50 & $34.7 \pm 1.72$ & $25.1 \pm 2.90$ \\
\hline 10 & 100 & $40.4 \pm 1.85$ & $26.3 \pm 1.48$ & 50 & $28.5 \pm 1.64$ & $20.9 \pm 2.94$ \\
\hline 15 & 100 & $40.3 \pm 0.7$ & $28.3 \pm 0.61$ & 40 & $21.2 \pm 3.68$ & $17.3 \pm 1.66$ \\
\hline 20 & 100 & $38.6 \pm 1.2$ & $25.7 \pm 1.57$ & 40 & $14.2 \pm 1.07$ & $10.9 \pm 2.18$ \\
\hline 25 & 100 & $40.2 \pm 1.8$ & $26.3 \pm 1.61$ & 30 & $10.9 \pm 1.77$ & $8.09 \pm 3.57$ \\
\hline 30 & 100 & $41.6 \pm 2.1$ & $29.7 \pm 1.17$ & 30 & $5.8 \pm 2.01$ & $4.31 \pm 2.53$ \\
\hline
\end{tabular}

VWC: volumetric water content; SWC: soil water content

$n=294$ for VWC and $n=16$ for SWC 
The photosynthetic rate $(\mathrm{Pn})$, stomatal conductance $\left(g_{\mathrm{s}}\right)$, intercellular $\mathrm{CO}_{2}$ concentration $\left(\mathrm{C}_{\mathrm{i}}\right)$ and transpiration rate $(\mathrm{Tr})$ were measured using a portable photosynthesis system (Li-6400XT, LI-COR, Inc., Lincoln, NE, USA) under a controlled atmosphere $\left(385 \mu \mathrm{mol} \mathrm{mol}^{-1}\right.$ $\mathrm{CO}_{2}, 500 \mu \mathrm{mol} \mathrm{s}^{-1}$ flow rate, $26^{\circ} \mathrm{C}$ ) and a LI-COR 6400 LED external light source that provided a photosynthetic photon flux density (PPFD) of $2000 \mu \mathrm{mol} \mathrm{m}{ }^{-2} \mathrm{~s}^{-1}$. The uppermost fully expanded leaf on the main tiller in each pot was selected for these measurements. Three readings were collected for each sample, and the average was used for statistical analysis.

\section{Metabolite extraction and derivatization}

We analyzed a total of 14 drought stress tolerance-related metabolites [53, 61, 62], including ABA, JA, JA-Ile, betaine, proline, putrescine, spermine, spermidine, fructose, glucose, inositol, sucrose, trehalose, and raffinose.

Plant tissues were frozen in liquid nitrogen, lyophilized overnight and transferred to 2-mL screw-cap tubes (http://www.sarstedt.com) containing three 3.2mm stainless steel beads (http://www.biospec.com). The tissue was ground, and aliquots of approximately $50 \mathrm{mg}$ were automatically transferred to new tubes using the iWall instrument at the GLBRC Cell Wall facility at Michigan State University (https://www.glbrc.org/ research/enabling-technologies). Chemical extraction was performed using a $10 \%$ methanol and $1 \%$ acetic acid solvent containing internal standards of $10 \mu \mathrm{M}$ dh-JA, $10 \mu \mathrm{M}$ ribitol, $10 \mu \mathrm{M}\left[{ }^{2} \mathrm{H}_{3}\right]$ proline, and $1 \mu \mathrm{M}$ $\left[{ }^{2} \mathrm{H}_{6}\right]$ ABA. For extraction, $400 \mu \mathrm{L}$ of extraction solvent was added to approximately $50 \mathrm{mg}$ of ground plant tissue, and the mixture was incubated at $70{ }^{\circ} \mathrm{C}$ for $30 \mathrm{~min}$. The extract was centrifuged for $15 \mathrm{~min}$ at $13,000 \mathrm{rpm}$, and $200 \mu \mathrm{L}$ of supernatant was transferred to a new 1.5-mL microcentrifuge tube. For each plant, $60 \mu \mathrm{L}$ of extract was transferred to each of two 96-well PCR tubes for the analysis of two groups of metabolites: (1) ABA, JA, and JA-Ile, and (2) polyamines and proline. For sugar analysis using GC-MS, $10 \mu \mathrm{L}$ of the extract was transferred to a new $1.5-\mathrm{ml}$ microcentrifuge tube for derivatization. For derivatization, $10 \mu \mathrm{L}$ of extract was evaporated to complete dryness overnight using a SpeedVac. Ten microliters of $40 \mathrm{mg} \mathrm{mL}^{-1} \mathrm{O}$-methylhydroxylamine hydrochloride in pyridine was added to the dried plant extract and the tubes incubated for $90 \mathrm{~min}$ at $30{ }^{\circ} \mathrm{C}$ with gentle rocking. Forty-five microliters of $N$-methyl- $N$-trimethylsilyltrifluoroacetamide (MSTFA) with $1 \%$ trimethylchlorosilane (TMCS) was then added to the mixture, and the tubes incubated at $37{ }^{\circ} \mathrm{C}$ for an additional $30 \mathrm{~min}$. For sugar analysis, 50 $\mu \mathrm{L}$ of the derivatized product was transferred to a glass vial containing a glass insert (http://www.restek.com). All materials were barcoded to keep track of each sample throughout the entire extraction and derivatization procedure.

\section{Metabolite determination using GC-MS}

To analyze the plants' sugar profiles, GC-MS was performed using a $6890 \mathrm{~N}$ network GC system with a 5973 mass selective detector (Agilent Technologies, http:// www.agilent.com, Santa Clara, CA, USA). Separation was achieved by injection of $1 \mu \mathrm{L}$ of derivatized extract into a 30-m VF-5 MS column $(30 \mathrm{~m} \times 0.25 \mathrm{~mm} \times 0.25 \mu \mathrm{M}$; Agilent), with a 10-m EZ-Guard (Agilent), using the following temperature profile: $80^{\circ} \mathrm{C}$ for $1 \mathrm{~min} ; 40^{\circ} \mathrm{C} \mathrm{min}-1$ to $220^{\circ} \mathrm{C}$ for $3 \mathrm{~min} ; 40{ }^{\circ} \mathrm{C} \mathrm{min}^{-1}$ to $320^{\circ} \mathrm{C}$ for $6 \mathrm{~min}$; and $270{ }^{\circ} \mathrm{C}$ for $1 \mathrm{~min}$. Sugar metabolites were detected using selected ion monitoring (SIM) mode with $\mathrm{m} / \mathrm{z}$ values of 205.2, 217.0, 217.2, 305.0, 307.2, 319.2, 319.3, and 361.3 throughout the GC-MS run.

\section{Metabolite analysis using LC-MS/MS}

For the analysis of ABA, JA, and JA-Ile, methods from Chung et al. [63] were used with modifications. Briefly, extracts $(10 \mu \mathrm{L})$ were injected into an Ascentis Express C18 column $(2.7 \mu \mathrm{M}, 2.1 \times 50 \mathrm{~mm}$, Supelco Analytical) and attached to an Acquity Ultraperformance Liquid Chromatography System (Waters, http://www. waters.com, Milford, MA, USA) for LC reverse-phase analysis. The column temperature was maintained at $50{ }^{\circ} \mathrm{C}$. A steep gradient was executed between solvents $\mathrm{A}$ and $\mathrm{B}(\mathrm{A}-0.15 \%$ formic acid in MilliQ water, $\mathrm{B}-$ methanol) with an analysis time of $3 \mathrm{~min} / \mathrm{sample}$ and a $0.4 \mathrm{~mL} \mathrm{~min}^{-1}$ flow rate. The gradient profile was as follows: $30 \% \mathrm{~B}$ for the initial step; a linear gradient to $70 \% \mathrm{~B}$ in $1.5 \mathrm{~min} ; 100 \% \mathrm{~B}$ in $2 \mathrm{~min} ; 100 \% \mathrm{~B}$ maintained for $2.5 \mathrm{~min}$; and $30 \% \mathrm{~B}$ from $2.5 \mathrm{~min}$ to 3 min. Mass spectra were acquired using electrospray ionization in negative ion mode and multiple reaction monitoring (MRM). A Quattro Premier XE tandem quadrupole mass spectrometer (Waters) was coupled to the LC to identify and detect analytic signals under the following conditions: $3.00 \mathrm{kV}$ capillary voltage; $100{ }^{\circ} \mathrm{C}$ source temperature; $300{ }^{\circ} \mathrm{C}$ desolvation temperature; $20 \mathrm{~L} \mathrm{~h}^{-1}$ nebulizer nitrogen flow rate; and $300 \mathrm{~L}$ $\mathrm{h}^{-1}$ desolvation nitrogen gas flow rate. The transitions from precursor molecules to characteristic product ions were monitored for JA $(m / z 209>59)$, dh-JA $(m / z$ $211>59)$, JA-Ile $(m / z 322>130)$, ABA $(m / z 263>153)$, and $\left[{ }^{2} \mathrm{H}_{6}\right]$ ABA $(m / z 269>159)$. The collision energies and source cone potentials were optimized for each transition using Waters QuanOptimize software. Because this method does not distinguish JA-Ile from 
JA-Leu, the values reported for JA-Ile represent the sum of JA-Ile and JA-Leu. In Arabidopsis seedlings, the amount of JA-Leu is reported to be $<25 \%$ that of JA-Ile [64].

For the analysis of putrescine and spermine, methods from $\mathrm{Gu}$ et al. [65] were used with modifications. Briefly, the extracts $(10 \mu \mathrm{L})$ were injected into a Symmetry C18 column $(2.1 \times 100 \mathrm{~mm}, 3.5 \mu \mathrm{M}$ particle size, Waters $)$ and attached to a Shimadzu (Columbia, MD, USA) LC-20AD HPLC system for LC reverse-phase analysis. The column temperature was maintained at $30{ }^{\circ} \mathrm{C}$. A steep gradient was executed between solvents $A$ and $B(A-1 \mathrm{mM}$ perfluoroheptanoic acid in MilliQ water, B-acetonitrile) with an analysis time of $6 \mathrm{~min} / \mathrm{sample}$ and a $0.3 \mathrm{~mL} \mathrm{\textrm {min } ^ { - 1 }}$ flow rate. The gradient profile was as follows: $2 \% \mathrm{~B}$ for the initial step; a linear gradient to $20 \% \mathrm{~B}$ in $0.1 \mathrm{~min}$; $80 \% \mathrm{~B}$ in $2.5 \mathrm{~min}$; $80 \% \mathrm{~B}$ maintained for $4 \mathrm{~min} ; 20 \% \mathrm{~B}$ in $4.1 \mathrm{~min}$; and $2 \% \mathrm{~B}$ in $6 \mathrm{~min}$. Mass spectra were acquired using electrospray ionization in positive ion mode and MRM. A Quattro micro mass spectrometer (Waters) was coupled to the LC to identify and detect analytic signals under the following conditions: electrospray negative ionization mode; $3.17 \mathrm{kV}$ capillary voltage; $110^{\circ} \mathrm{C}$ source temperature; $350{ }^{\circ} \mathrm{C}$ desolvation temperature; $20 \mathrm{~L} \mathrm{~h}^{-1}$ nebulizer nitrogen flow rate; and $400 \mathrm{~L} \mathrm{~h}^{-1}$ desolvation nitrogen gas flow rate. The transitions from precursor molecules to characteristic product ions were monitored for putrescine $(m / z 89>72)$, proline $(m / z 116>70)$, betaine $(m / z 118>59)$, $\left[{ }^{2} \mathrm{H}_{3}\right]$ proline $(m / z 119>73)$, spermidine $(m / z 146>72)$, and spermine $(203>112)$. The collision energies and source cone potentials were optimized for each transition using Waters QuanOptimize software.

\section{Drought tolerance evaluation}

To assess the drought tolerance of different populations, the drought stress index (DSI) was used in this study. DSI was calculated using the formula: DSI = (value of trait under stress condition)/(value of trait under controlled condition) $\times 100$ [15].

To assess the drought tolerance of different genotypes, the PCA ranking value was used in this study. The PCA ranking value for each switchgrass genotype was calculated using the formula:

Ranking value $=$ (contribution of $\mathrm{PC} 1$ $(\%) \times \mathrm{PC} 1)+($ contribution of $\mathrm{PC} 2(\%) \times \mathrm{PC} 2)+($ contribution of $\mathrm{PC} 3(\%) \times \mathrm{PC} 3)$ [44].

\section{DNA extraction and genetic diversity analysis}

DNA was extracted from approximately $200 \mathrm{mg}$ of leaf tissue from each of the 49 genotypes using the CTAB method [66]. The quality of the DNA was assessed by electrophoresis on $0.8 \%$ agarose gels, and the quantity of the DNA was measured by comparing the samples to standardized lambda DNA size markers.

For SRAP-PCR amplification, 12 pairs of previously reported SRAP primers were selected for this study (Table 2) [67]. SRAP analysis was performed as described previously [40]. Briefly, each $20 \mu \mathrm{L}$ PCR reaction mixture consisted of $40 \mathrm{ng}$ genomic DNA, $0.2 \mathrm{mM}$ dNTPs, $2.5 \mathrm{mM} \mathrm{MgCl} 2,0.5 \mu \mathrm{M}$ primers, $1 \times$ PCR buffer, and 1 unit of Taq polymerase. The amplification was performed in four steps: pre-denaturation at $94{ }^{\circ} \mathrm{C}$ for $4 \mathrm{~min} ; 5$ cycles of 1 min denaturation at $94{ }^{\circ} \mathrm{C}, 1 \mathrm{~min}$ annealing at $35^{\circ} \mathrm{C}$ and $1.5 \mathrm{~min}$ extension at $72{ }^{\circ} \mathrm{C} ; 35$ cycles of $1 \mathrm{~min}$ at $94{ }^{\circ} \mathrm{C}, 1 \mathrm{~min}$ at $50{ }^{\circ} \mathrm{C}$, and $1.5 \mathrm{~min}$ at $72{ }^{\circ} \mathrm{C}$; and a final extension step at $72{ }^{\circ} \mathrm{C}$ for $7 \mathrm{~min}$. The PCR fragments were separated on a $5 \%$ agarose gel, stained with $0.01 \%$ ethidium bromide, and visualized using a Gel-Document Image System $^{\mathrm{TM}}$ under UV light (Bio-Rad, Hercules, CA, USA).

\section{Experimental design and statistical analysis}

A split plot design was used in this experiment, with the soil moisture regimes as the main plots and the switchgrass genotypes as the subplots. Each genotype had six replicates for each soil moisture treatment (well-watered and drought). All data were subjected to analysis of variance (ANOVA, SAS 8.1, SAS Institute Inc., Cary, NC, USA). The treatment means were separated using Fisher's protected least significant difference (LSD) test at a $5 \%$ probability level.

$\mathrm{R}$ statistical software (PCA analysis, $\mathrm{R} 2.15 .1$ by $\mathrm{R}$ Development Core Team) was used to determine the correlations between physiological and morphological traits and to perform principal component analysis of the traits.

Each genomic DNA fragment obtained from the SRAP primer combinations was scored as present (1) or absent (0). These data were used to calculate genetic distances and to draw genetic distance dendrograms of the 49 switchgrass genotypes. The dendrograms were drawn using NTSYS-pc version 2.2 and were based on the DICE matrix and UPGMA (Unweighted Pair Group Method) arithmetical averages in the SAHN module. Concordance between the genotypic data and the dendrogram was determined using a Mantel test [68]. In addition, genetic distance dendrograms were drawn using DARwin5 software, which is based on the DICE matrix and UPGMA in the hierarchical clustering module and on unweighted neighbor-joining in the neighbor-joining module. 


\section{Additional files}

Additional file 1: Figure S1. Principal component analysis biplot of morphological and physiological traits of 49 switchgrass genotypes under well-watered and drought stress conditions after 15 days of treatment. The seven physiological parameters (Pn, $\mathrm{Ci}, g_{s}, \mathrm{Tr}$, RWC, WUE and EL) allow to separate 49 switchgrass genotypes that were either grown under well-watered (circled) or drought treatment (box) conditions. Arrows represent physiological traits with various length based on the impact of each trait on the separation of genotypes. RWC: relative water content; EL: electrolyte leakage; $\mathrm{Pn}$ : photosynthetic rate; $\mathrm{g}_{\mathrm{s}}$ : stomatal conductance; Tr: transpiration rate; $\mathrm{Ci}$ : intercellular $\mathrm{CO}_{2}$ concentration; WUE: water use efficiency. LL: leaf length; LW: leaf width; SL: leaf sheath length. Group A: well-watered; Group B: drought treatment.

Additional file 2. Effect of drought stress on morphological parameters at $30 \mathrm{~d}$ of experiment $(n=6)$, and effect of drought stress on morphological parameters of lowland and upland lines at $30 \mathrm{~d}$ of experiment, $(n=294)$. LL: leaf length; LW: leaf width; SL: leaf sheath length; SE: standard error.

Additional file 3: Figure S2. The photosynthetic rate (Pn) of 49 genotypes under well-watered conditions (control, solid bar) or drought stress (open bar) after 30 days of treatment. The genotype represents the DSI. The greater the DSI, the better the drought tolerance. The values are the means $(n=6)$.The bar represents LSD (0.05) for DSI.

Additional file 4: Figure S3. The stomatal conductance $\left(g_{\mathrm{s}}\right)$ of 49 geno types under well-watered conditions (control, solid bar) or drought stress (open bar) after 30 days of treatment. The genotype represents the DSI. The greater the DSI, the better the drought tolerance. The values are the means $(n=6)$. The bar represents LSD (0.05) for DSI.

Additional file 5: Figure S4. The transpiration rate ( $\mathrm{Tr}$ ) of 49 genotypes under well-watered conditions (control, solid bar) or drought stress (open bar) after 30 days of treatment. The genotype represents the DSI. The greater the DSI, the better the drought tolerance. The values are the means ( $n=6)$. The bar represents LSD (0.05) for DSI.

Additional file 6: Figure S5 The intercellular $\mathrm{CO}_{2}$ concentration (Ci) of 49 genotypes under well-watered conditions (control, solid bar) or drought stress (open bar) after 30 days of treatment. The genotype represents the DSI. The greater the DSI, the better the drought tolerance. The values are the means $(n=6)$. The bar represents LSD (0.05) for DSI.

Additional file 7: Figure S6. The relative water content (RWC) of leaves from 49 genotypes under well-watered conditions (control, solid bar) or drought stress (open bar) after 30 days of treatment. The genotype represents the DSI. The greater the DSI, the better the drought tolerance. The values are the means of four replicates $(n=6)$. The bar represents LSD (0.05) for DSI.

Additional file 8: Figure S7. The water use efficiency (WUE) of 49 genotypes under well-watered conditions (control, solid bar) or drought stress (open bar) after 30 days of treatment. The genotype represents the DSI. The greater the DSI, the better the drought tolerance. The values are the means $(n=6)$. The bar represents LSD (0.05) for DSI.

Additional file 9: Figure S8. The leaf electrolyte leakage (EL) of 49 genotypes under well-watered conditions (control, solid bar) or drought stress (open bar) after 30 days of treatment. The genotype represents the DSI. The lower the DSI, the better the drought tolerance. The values are the means $(n=6)$. The bar represents LSD (0.05) for DSI.

Additional file 10: Figure S9. Proportion of variance for principa component analysis based on the DSI of seven physiological traits of 49 switchgrass genotypes under well-watered (control) and drought stress conditions after 30 days of treatment.

\section{Abbreviations}

ET: evapotranspiration; RWC: relative water content; EL: electrolyte leakage; Pn: photosynthetic rate; Gs: stomatal conductance; Tr: transpiration; SRAP: sequence-related amplified polymorphism; Ci: intercellular $\mathrm{CO}_{2}$ concentration; WUE: water use efficiency; PCA: principal component analysis; ABA: abscisic acid; JA: jasmonic acid; JA-Ile: jasmonic acid-isoleucine; GB: glycine betaine; PAs: polyamines; LL: leaf length; LW: leaf width; SL: leaf sheath length.

\section{Authors' contributions}

$X Z, K C, B Z$ conceived the study as well as participated in its design and coordination. $Y L$ and $X Z$ carried out all drought treatment experiments. HT and LS performed the statistical analysis. JK and KC performed the metabolites analysis. $Y L, X Z, K C$, and $B Z$ analyzed the data and wrote the manuscript. All authors suggested revisions to the drafts manuscript, read, and approved the final manuscript.

\section{Author details}

${ }^{1}$ Department of Crop and Soil Environmental Science, Virginia Tech, 367 Smyth Hall, 185 Ag Quad Ln, Blacksburg, VA 24061, USA. ${ }^{2}$ Department of Statistics, Virginia Tech, Blacksburg, VA, USA. ${ }^{3}$ Department of Plant Biology, Michigan State University, East Lansing, MI, USA. ${ }^{4}$ Center for Genomics-Enabled Plant Science, Michigan State University, East Lansing, MI, USA. ${ }^{5}$ Department of Horticulture, Virginia Tech, 407 Latham Hall, 220 Ag Quad Ln, Blacksburg, VA 24061, USA.

\section{Acknowledgements}

We thank Dr. John Seiler, Mr. John Peterson, Dr. Jacob Barney (Virginia Tech) for support with equipment, George Tolton, Alyssa Hamill, and Mattia Accorsi for the help in this study. The project was supported by a grant from the program of Plant Feedstock Genomics for Bioenergy of the US Department of Agriculture and the US Department of Energy (KC, RB, XZ, and BZ). The study was also partially supported by Virginia Tech's Virginia Agricultural Experiment Station (VA135872 to BZ).

\section{Compliance with ethical guidelines}

\section{Competing interests}

The authors declare that they have no competing interests.

Received: 6 March 2015 Accepted: 10 September 2015

Published online: 22 September 2015

\section{References}

1. McLaughlin SB, Adams Kszos L. Development of switchgrass (Panicum virgatum) as a bioenergy feedstock in the United States. Biomass Bioenergy. 2005;28(6):515-35. doi:10.1016/j.biombioe.2004.05.006.

2. Wright L, Turhollow A. Switchgrass selection as a "model" bioenergy crop: a history of the process. Biomass Bioenergy. 2010;34(6):851-68. doi:10.1016/j.biombioe.2010.01.030

3. Jones MB. Switchgrass - a valuable biomass crop for energy. Crop Sci. 2013;53(1):351. doi:10.2135/cropsci2012.12.0004br.

4. Jiang Y, Yao Y, Wang Y. Physiological response, cell wall components, and gene expression of switchgrass under short-term drought stress and recoveries. Crop Sci. 2012;52(6):2718-27. doi:10.2135/ cropsci2012.03.0198.

5. Morrow lii WR, Gopal A, Fitts G, Lewis S, Dale L, Masanet E. Feedstock loss from drought is a major economic risk for biofuel producers. Biomass and Bioenergy. 2014;69:135-43. doi:10.1016/j.biombioe.2014.05.006.

6. Ashraf M. Inducing drought tolerance in plants: recent advances. Biotechnol Adv. 2010;28(1):169-83. doi:10.1016/j.biotechadv.2009.11.005.

7. Hopkins AA, Taliaferro CM, Murphy CD, Christian DA. Chromosome number and nuclear DNA content of several switchgrass populations. Crop Sci. 1996;36(5):1192-5. doi:10.2135/cropsci1996.0011183X00360005 0021x.

8. Zhang Y, Zalapa J, Jakubowski AR, Price DL, Acharya A, Wei Y, et al. Natural hybrids and gene flow between upland and lowland switchgrass. Crop Sci. 2011;51(6):2626-41.

9. Serba D, Wu L, Daverdin G, Bahri BA, Wang X, Kilian A, et al. Linkage maps of lowland and upland tetraploid switchgrass ecotypes. BioEnergy Res. 2013;6(3):953-65. doi:10.1605/01.301-0023821934.2013. 
10. Barney JN, Mann JJ, Kyser GB, et al. Tolerance of switchgrass to extreme soil moisture stress: ecological implications. Plant Sci. 2009;177(6):724-32.

11. Fahej MAS. Screening switchgrass (Panicum virgatum L.) for water stress tolerance and utilizing in vitro culture technique to induce variation. 2012

12. Berdahl JD, Frank AB, Krupinsky JM, Carr PM, Hanson JD, Johnson HA. Biomass yield, phenology, and survival of diverse switchgrass cultivars and experimental strains in western north dakota USDA-ARS, northern plains area, is an equal opportunity/affirmative action employer, and all agency services are available without discrimination. Agron J. 2005;97(2):549-55. doi:10.2134/agronj2005.0549.

13. Porter CL. An analysis of variation between upland and lowland switchgrass, Panicum Virgatum L., in Central Oklahoma. Ecology. 1966;47(6):98092. doi:10.2307/1935646.

14. Stroup JA, Sanderson MA, Muir JP, McFarland MJ, Reed RL. Comparison of growth and performance in upland and lowland switchgrass types to water and nitrogen stress. Bioresour Technol. 2003;86(1):65-72. doi:10.1016/S0960-8524(02)00102-5.

15. Wójcik-Jagła M, Rapacz M, Tyrka M, Kościelniak J, Crissy K, Żmuda K. Comparative QTL analysis of early short-time drought tolerance in Polish fodder and malting spring barleys. TAG Theor Appl Genet. 2013;126(12):3021-34. doi:10.1007/s00122-013-2190-x.

16. Tazaki T, Ishihara K, Ushijima T. Influence of water stress on the photosynthesis and productivity of plants in humid stress. Adaptation of plants for water and high temperature stress. New York: Wiley; 1980. p. 309-22.

17. Farooq M, Wahid A, Kobayashi N, Fujita D, Basra SMA. Plant drought stress: effects, mechanisms and management. Agron Sustain Dev. 2009;29(1):185-212. doi:10.1051/agro:2008021.

18. Mahajan S, Tuteja N. Cold, salinity and drought stresses: an overview. Arch Biochem Biophys. 2005;444(2):139-58. doi:10.1016/j.abb.2005.10.018.

19. Sivamani E, Bahieldin A, Wraith JM, Al-Niemi T, Dyer WE, Ho TD, et al. Improved biomass productivity and water use efficiency under water deficit conditions in transgenic wheat constitutively expressing the barley HVA1 gene. Plant Sci Int J Exp Plant Biol. 2000;155(1):1-9.

20. Yige C, Fangqing C, Lei L, Shunbo Z. Physiological responses of Leucaena leucocephala seedlings to drought stress. Procedia Eng. 2012;28:110-6. doi:10.1016/j.proeng.2012.01.691.

21. Sun J, Luo H, Fu J, Huang B. Classification of genetic variation for drought tolerance in Tall Fescue using physiological traits and molecular markers. Crop Sci. 2013;53(2):647-54. doi:10.2135/cropsci2012.05.0315

22. Chaves MM, Flexas J, Pinheiro C. Photosynthesis under drought and salt stress: regulation mechanisms from whole plant to cell. Ann Bot. 2009;103(4):551-60. doi:10.1093/aob/mcn125.

23. Zhang J, Jia W, Yang J, Ismail AM. Role of ABA in integrating plant responses to drought and salt stresses. Field Crops Res. 2006;97(1):111-9. doi:10.1016/j.fcr.2005.08.018.

24. de Ollas C, Hernando B, Arbona V, Gomez-Cadenas A. Jasmonic acid transient accumulation is needed for abscisic acid increase in citrus roots under drought stress conditions. Physiol Plant. 2013;147(3):296-306. doi:10.1111/j.1399-3054.2012.01659.x.

25. Alam MM, Nahar K, Hasanuzzaman M, Fujita M. Exogenous jasmonic acid modulates the physiology, antioxidant defense and glyoxalase systems in imparting drought stress tolerance in different Brassica species. Plant Biotechnol Rep. 2014;8(3):279.

26. Medeiros DB, Silva ECD, Santos HRB, Pacheco CM, Musser RDS, Nogueira RJMC. Physiological and biochemical responses to drought stress in Barbados cherry. Braz J Plant Physiol. 2012;24:181-92.

27. Parida A, Dagaonkar V, Phalak M, Aurangabadkar L. Differential responses of the enzymes involved in proline biosynthesis and degradation in drought tolerant and sensitive cotton genotypes during drought stress and recovery. Acta Physiol Plant. 2008;30(5):619-27. doi:10.1007/ s11738-008-0157-3.

28. Desmarais DL, McKay JK, Richards JH, Sen S, Wayne T, Juenger TE. Physiological genomics of response to soil drying in diverse Arabidopsis accessions. Plant Cell. 2012;24(3):893-914. doi:10.1105/tpc.112.096180.

29. Patel JA, Vora AB. Free proline accumulation in drought-stressed plants. Plant Soil. 1985;84(3):427-9. doi:10.1007/BF02275480

30. Van Rensburg L, Krüger GHJ, Krüger H. Proline accumulation as droughttolerance selection criterion: its relationship to membrane integrity and chloroplast ultrastructure in Nicotiana tabacum L. J Plant Physiol. 1993;141(2):188-94. doi:10.1016/S0176-1617(11)80758-3.

31. Naser $L$, Kourosh V, Bahman K, Reza A. Soluble sugars and proline accumulation play a role as effective indices for drought tolerance screening in Persian walnut (Juglans regia L.) during germination. Fruits. 2010;65(02):97-112. doi:10.1051/fruits/20010005.

32. Wang GP, Zhang XY, Li F, Luo Y, Wang W. Overaccumulation of glycine betaine enhances tolerance to drought and heat stress in wheat leaves in the protection of photosynthesis. Photosynthetica. 2010;48(1):117-26. doi:10.1007/s11099-010-0016-5.

33. Schroeder JI, Kwak JM, Allen GJ. Guard cell abscisic acid signalling and engineering drought hardiness in plants. Nature. 2001;410(6826):327-30.

34. Alcázar R, Bitrián M, Bartels D, Koncz C, Altabella T, Tiburcio AF. Polyamine metabolic canalization in response to drought stress in Arabidopsis and the resurrection plant Craterostigma plantagineum. Plant Signal Behav. 2011;6(2):243-50

35. Montesinos-Pereira D, Barrameda-Medina Y, Romero L, Ruiz JM, SanchezRodriguez E. Genotype differences in the metabolism of proline and polyamines under moderate drought in tomato plants. Plant Biol. 2014; doi:10.1111/plb.12178.

36. Yang J, Zhang J, Liu K, Wang Z, Liu L. Involvement of polyamines in the drought resistance of rice. J Exp Bot. 2007;58(6):1545-55. doi:10.1093/jxb/erm032.

37. Cortese L, Honig J, Miller C, Bonos S. Genetic diversity of twelve switchgrass populations using molecular and morphological markers. BioEnergy Res. 2010;3(3):262-71. doi:10.1007/s12155-010-9078-2.

38. Lu F, Lipka AE, Glaubitz J, Elshire R, Cherney JH, Casler MD, et al. Switchgrass genomic diversity, ploidy, and evolution: novel insights from a network-based snp discovery protocol. PLoS Genet. 2013;9(1):e1003215. doi:10.1371/journal.pgen.1003215.

39. Zhang Y, Zalapa JE, Jakubowski AR, Price DL, Acharya A, Wei Y, et al. Post-glacial evolution of Panicum virgatum: centers of diversity and gene pools revealed by SSR markers and cpDNA sequences. Genetica. 2011;139(7):933-48. doi:10.1007/s10709-011-9597-6.

40. Li G, Quiros CF. Sequence-related amplified polymorphism (SRAP), a new marker system based on a simple PCR reaction: its application to mapping and gene tagging in Brassica. Theor Appl Genet. 2001;103(2-3):45561. doi:10.1007/s001220100570.

41. Aneja B, Yadav N, Chawla V, Yadav R. Sequence-related amplified polymorphism (SRAP) molecular marker system and its applications in crop improvement. Mol Breeding. 2012;30(4):1635-48. doi:10.1007/ s11032-012-9747-2.

42. Lin Z, Zhang $X$, Nie $Y$, He D, Wu M. Construction of a genetic linkage map for cotton based on SRAP. Chin Sci Bull. 2003;48(19):2064-8. doi:10.1360/03wc0193.

43. Liu Y, Zhang X, Miao J, Huang L, Frazier T, Zhao B. Evaluation of salinity tolerance and genetic diversity of thirty-three switchgrass (Panicum virgatum) populations. BioEnergy Res. 2014;7(4):1329-42. doi:10.1007/ s12155-014-9466-0.

44. Zhu X, Chang G, He D, Zhao H, Ma C. Evaluation of new onion varieties using cluster analysis and principal component analysis methods. Gansu Agr Sci. 2014;10:25-8.

45. Sakhi S. Shafiq ur R, Okuno K, Shahzad A, Jamil M. Evaluation of sorghum (Sorghum bicolor) core collection for drought tolerance: pollen fertility and mean performance of yield traits and Its components at reproductive stage. Int J Agric Biol. 2014;16(2):251-60.

46. Gholami M, Rahemi M, Rastegar S. Use of rapid screening methods for detecting drought tolerant cultivars of fig (Ficus carica L.). Sci Hortic. 2012;143:7-14. doi:10.1016/j.scienta.2012.05.012.

47. Nazari L, Pakniyat H. Assessment of drought tolerance in barley genotypes. J Appl Sci (Faisalabad). 2010;10(2):151-6. doi:10.3923/jas.2010.151.156.

48. Dehbalaei S, Farshadfar E, Farshadfar M. Assessment of drought tolerance in bread wheat genotypes based on resistance/tolerance indices. Int $J$ Agric Crop Sci. 2013;5(20):2352-8.

49. Mittler R. Oxidative stress, antioxidants and stress tolerance. Trends Plant Sci. 2002;7(9):405-10.

50. McDowell N, Pockman WT, Allen CD, Breshears DD, Cobb N, Kolb T, et al. Mechanisms of plant survival and mortality during drought: why do some plants survive while others succumb to drought? New Phytol. 2008;178(4):719-39. doi:10.1111/j.1469-8137.2008.02436.x.

51. Rachmilevitch S, Huang B, Lambers H. Assimilation and allocation of carbon and nitrogen of thermal and nonthermal Agrostis species in 
response to high soil temperature. New Phytol. 2006;170(3):479-90. doi:10.1111/j.1469-8137.2006.01684.x.

52. Alcazar R, Bitrian M, Bartels D, Koncz C, Altabella T, Tiburcio AF. Polyamine metabolic canalization in response to drought stress in Arabidopsis and the resurrection plant Craterostigma plantagineum. Plant Signal Behav. 2011;6(2):243-50

53. Silvente S, Sobolev AP, Lara M. Metabolite adjustments in drought tolerant and sensitive soybean genotypes in response to water stress. PLOS One. 2012;7(6):e38554. doi:10.1371/journal.pone.0038554.

54. Bruce WB, Edmeades GO, Barker TC. Molecular and physiological approaches to maize improvement for drought tolerance. J Exp Bot. 2002;53(366):13-25

55. Merewitz EB, Gianfagna T, Huang B. Photosynthesis, water use, and root viability under water stress as affected by expression of SAG12ipt controlling cytokinin synthesis in Agrostis stolonifera. J Exp Bot. 2011;62(1):383-95. doi:10.1093/jxb/erq285.

56. Blum A. Effective use of water (EUW) and not water-use efficiency (WUE) is the target of crop yield improvement under drought stress. Field Crops Res. 2009;112(2-3):119-23. doi:10.1016/j.fcr.2009.03.009.

57. Missaoui A, Paterson A, Bouton J. Molecular markers for the classification of switchgrass (Panicum virgatum L.) germplasm and to assess genetic diversity in three synthetic switchgrass populations. Genet Resour Crop Evol. 2006;53(6):1291-302. doi:10.1007/s10722-005-3878-9.

58. Hardin CF, Fu C, Hisano H, Xiao X, Shen H, Stewart CN Jr, et al. Standardization of switchgrass sample collection for cell wall and biomass trait analysis. BioEnergy Res. 2013;6(2):755-62. doi:10.1007/s12155-012-9292-1.

59. Zhang X, Ervin EH. Cytokinin-containing seaweed and humic acid extracts associated with creeping bentgrass leaf cytokinins and drought resistance. Crop Sci. 2004;44(5):1737-45. doi:10.2135/cropsci2004.1737.
60. Marcum KB, Anderson SJ, Engelke MC. Salt gland ion secretion: a salinity tolerance mechanism among five zoysiagrass species. Crop Sci. 1998;38(5):1414.

61. Bowne JB, Erwin TA, Juttner J, Schnurbusch T, Langridge P, Bacic A, et al. Drought responses of leaf tissues from wheat cultivars of differing drought tolerance at the metabolite level. Mol Plant. 2012;5(2):418-29. doi:10.1093/Mp/Ssr114.

62. Dinakar C, Bartels D. Desiccation tolerance in resurrection plants: new insights from transcriptome, proteome and metabolome analysis. Front Plant Sci. 2013;4:482. doi:10.3389/fpls.2013.00482.

63. Chung HS, Koo AJ, Gao X, Jayanty S, Thines B, Jones AD, et al. Regulation and function of Arabidopsis JASMONATE ZIM-domain genes in response to wounding and herbivory. Plant Physiol. 2008;146(3):952-64. doi:10.1104/pp.107.115691.

64. Staswick PE. The Tryptophan conjugates of jasmonic and indole-3-acetic acids are endogenous auxin inhibitors. Plant Physiol. 2009;150(3):131021. doi: $10.2307 / 40538095$.

65. Gu L, Jones AD, Last RL. LC-MS/MS assay for protein amino acids and metabolically related compounds for large-scale screening of metabolic phenotypes. Anal Chem. 2007;79(21):8067-75. doi:10.1021/ac070938b.

66. Zhang $X$, Wang L, Shou L. Modified CTAB method for extracting genomic DNA from wheat leaf. Agric Sci Technol. 2013;14(7):946-9.

67. Huang LK, Bughrara SS, Zhang XQ, Bales-Arcelo CJ, Bin X. Genetic diversity of switchgrass and its relative species in Panicum genus using molecular markers. Biochem Syst Ecol. 201 1;39(4-6):685-93.

68. Jensen RJ. Ntsys-Pc-numerical taxonomy and multivariate-analysis system-version 1.40. Q Rev Biol. 1989;64(2):250-2.

\section{Submit your next manuscript to BioMed Central and take full advantage of:}

- Convenient online submission

- Thorough peer review

- No space constraints or color figure charges

- Immediate publication on acceptance

- Inclusion in PubMed, CAS, Scopus and Google Scholar

- Research which is freely available for redistribution

Submit your manuscript at

www.biomedcentral.com/submit

C Biomed Central 